\title{
Effect of behavioural interventions on physical activity, weight loss, physical function, health-related quality of life and depression in people with multimorbidity: a systematic review of randomised controlled trials
}

\author{
Alessio Bricca ( $\sim$ abricca@health.sdu.dk) \\ University of Southern Denmark https://orcid.org/0000-0001-9717-918X \\ Madalina Jäger \\ University of Southern Denmark \\ Marie Johnston \\ University of Aberdeen \\ Graziella Zangger \\ University of Southern Denmark \\ Lasse K. Harris \\ University of Southern Denmark \\ Julie Midtgaard \\ University Hospitals Centre for Health Care Research https://orcid.org/0000-0003-2381-2127 \\ Søren T. Skou \\ University of Southern Denmark https://orcid.org/0000-0003-4336-7059
}

\section{Systematic Review}

Keywords: Physical activity, behavioural interventions, multimorbidity

Posted Date: February 5th, 2021

DOI: https://doi.org/10.21203/rs.3.rs-207686/v1

License: (c) This work is licensed under a Creative Commons Attribution 4.0 International License. Read Full License

Version of Record: A version of this preprint was published at International Journal of Behavioral Medicine on April 28th, 2022. See the published version at https://doi.org/10.1007/s12529-022-10092-8. 


\section{Abstract}

Background To investigate the effect of behavioural interventions targeting lifestyle behaviours on physical activity, weight loss, physical function, health-related quality of life and depression in people with multimorbidity and to investigate which Behaviour Change Techniques (BCTs) are associated with better outcomes.

Methods Systematic review of randomised controlled trials targeting lifestyle behaviours in people with multimorbidity following the Cochrane recommendations. Data sources included MEDLINE, EMBASE, CENTRAL and CINAHL up to June 19th, 2020 and screening reference list of Cochrane reviews including people with multimorbidity, ongoing systematic reviews of the MOBILIZE project, the WHO registry and citation tracking of included studies. Meta-analyses using random-effects model to assess the effect of behavioural interventions on physical activity, weight loss, physical function and health-related quality of life and depression. Meta-regression analyses and effectiveness ratios to investigate the impact of pre-specified mediators of effect estimates. Cochrane 'Risk of Bias Tool' 2.0 and the GRADE assessment to evaluate the overall quality of evidence.

Results Fourteen papers involving 1,378 people. Behavioural interventions had little to no effect on physical activity (standardised mean difference $0.38,95 \% \mathrm{Cl}-0.12$ to 0.61 - very low certainty) and the effect on weight loss is uncertain (BMI mean difference $-0.17,95 \% \mathrm{Cl}$ -1.17 to 0.83 - very low certainty) at the end-treatment follow-up (mean duration 23 weeks, SD 15). Small improvements were seen in health-related quality of life (SMD $0.29,95 \% \mathrm{Cl} 0.17$ to 0.42 - moderate certainty) and physical function (SMD $0.42,95 \% \mathrm{Cl} 0.12$ to 0.73 - low certainty), and moderate improvements were seen for depression symptoms (SMD $-0.70,95 \% \mathrm{Cl}-0.98$ to -0.42 - moderate certainty). Studies using the BCTs 'action planning' and 'social support (practical)' reported greater physical activity and weight loss. The effects of behavioural interventions diminished for all the outcomes at long-term follow-ups (mean duration of 36 weeks, SD 15).

Conclusions Behavioural interventions targeting lifestyle behaviours improve health-related quality of life and physical function, and reduce depression symptoms, whereas little to no effect was achieved on physical activity and weight loss in people with multimorbidity. However, the evidence for physical activity and weight loss were of low quality and the end-treatment benefits diminished over time.

\section{Systematic review protocol Open Science Framework: https://osf.io/r7pm5/}

\section{Introduction}

More than half of the elderly population lives with multiple chronic conditions (i.e. multimorbidity) (1). Compared to people living with single chronic conditions, people with multimorbidity are at increased risk of dying prematurely, being admitted to and have an increased length of stay at the hospital $(2,3)$, have poorer physical and psychosocial health, higher intake of multiple drugs and increased health care utilization $(4,5)$. This challenges the current usual care of people with multimorbidity focusing on single-disease management approaches as opposed to individualised, multimorbidity care $(6,7)$.

Individualised care for people with multimorbidity includes recommendations related to a healthy lifestyle (8). Physical activity is low in people with multimorbidity (9), although being a key behaviour for survival and overall health alongside a healthy diet, not smoking and low alcohol consumption (10). While interventions targeting lifestyle behaviours, including physical activity and diet, benefit people with single chronic conditions (11) and those at risk of developing chronic conditions (12), less is known about their effects in people with multimorbidity, which are often excluded from clinical trials (13). Similarly, while some Behaviour Change Techniques (BCTs) that is 'an observable, replicable and irreducible component of an intervention designed to alter or redirect causal processes that regulate behaviour such as action planning, self-monitoring and goal setting' (14) are strongly associated with improved helath behaviours in people without chronic conditions (11) less is known about their effect on people with multimorbidity.

Due to the complexity of multimorbidity, to provide individuliased care, it has been suggested to focus on specific combinations of conditions, linked by specific risk factors and pathogenesis (15-18). Osteoarthritis of the knee or hip, hypertension, type 2 diabetes, depression, heart failure, ischemic heart disease, and chronic obstructive pulmonary disease are among the leading causes of global disability (19). However, to our knowledge, no systematic reviews have investigated the effect of behavioural interventions and BCTs in the aforementioned combinations of (medical) conditions. 
This systematic review aims to investigate the effect of behavioural interventions and BCTs on behavioural, physical and psychosocial outcomes in people with at least two of the following chronic conditions: osteoarthritis of the knee or hip, hypertension, type 2 diabetes, depression, heart failure, ischemic heart disease, and chronic obstructive pulmonary disease.

\section{Methods}

We followed the Cochrane Handbook recommendations for performing systematic reviews (20) and reported this systematic review according to the Preferred Reporting Items for Systematic Reviews and Meta-analyses (PRISMA) guidelines (21). The protocol for this systematic review was made publicly available on the Open Science Framework website (22) before the title and abstract screening phase was initiated.

\section{Eligibility criteria}

Population. RCTs published in peer-reviewed journals including adults ( $\geq 18$ years old), reporting at least two of the following conditions: osteoarthritis of the knee or hip, heart failure, ischemic heart disease, hypertension (systolic blood pressure $\geq 140$ and diastolic blood pressure $\geq 90$ ), type 2 diabetes mellitus, chronic obstructive pulmonary disease and depression as defined by the studies or calculated based on baseline participant characteristics.

Interventions. Interventions targeting self-directed health behaviours, that is physical activity and/or weight loss. For example a multifaceted intervention targeted to increase physical activity and/or weight loss, among another lifestyle behaviours, delivered by health care providers, in group or one-to-one. We excluded interventions targeting health-care professional and those solely delivered via a digital solution (i.e., eHealth).

\section{Behaviour Change Technique (BCT) Coding}

Interventions were coded for BCTs using the Behaviour Change Technique Taxonomy (v1) (14) by two researchers (MJ and GZ). Each of the researchers coded all the interventions independently. Disagreements were resolved through discussion, and a third reviewer (MJ) mediated where a consensus could not be reached. MS and GZ are trained in using the taxonomy and practised coding BCTs before this task via the online BCT community (https://www.bct-taxonomy.com/). All the intervention elements that contain specific BCT were coded. Only intervention (components) that closely correspond to the definitions of the BCTs provided in the taxonomy were coded. Authors were contacted if data was missing or unclear, and intervention protocols (or manuals) were requested to aid the BCT coding, if they were not included in the RCT publications or as additional materials.

Comparators. Studies comparing interventions targeting self-directed health behaviours (i.e., physical activity and/or weight loss) to usual/standard, and comparator groups non-exposed such as wait-and-see treatments.

Outcomes. We included studies assessing at least one of the following outcomes:

- Behavioural outcome:

- Physical activity: Objectively measured or self-reported.

- Physical health outcomes:

- Weight loss

- Physical Function: Objectively measured or self-reported.

- Psychosocial health outcomes:

- Health-related quality of life. 
Physical activity and weight loss were the pre-specified primary outcomes (22). These outcomes were included to adhere to recommendations from a consensus paper on which outcomes to use in intervention studies, including people with multimorbidity (23). The choice of these outcomes was also supported by the patient partners of MOBILIZE who were invited to comment on the current systematic review and the outcome measures included.

Literature search. We searched for studies in the Cochrane Database of Systematic Reviews, MEDLINE via PubMed, EMBASE via Ovid, CINAHL (including preCINAHL) via EBSCO, and the World Health Organization International Clinical Trials Registry Platform (ICTRP). The search was performed on June 19th, 2020 and can be found as Additional file 1. Reference lists of the included articles and citation tracking were also performed using Web of Science. We also screened the latest Cochrane systematic review reference lists, including people with multimorbidity (17). Furthermore, we screened for completed trials in The World Health Organization's International Clinical Trials Registry Platform (ICTRP) http://apps.who.int/trialsearch/ comprising the 16 primary registries of the WHO registry network and ClinicalTrials.gov. We additionally searched Web of Science for studies citing the RCTs included in this systematic review (citations tracking).

Search method and study selection. The search strategy was developed for MEDLINE and was customised for EMBASE, CINAHL and CENTRAL (Additional file Table 1). All terms were searched both as keywords (Mesh) and as text words in title and abstract, when possible. We used the Cochrane sensitive search strategy for identifying RCTs. The literature search results were uploaded to Covidence, and two reviewers (AB and $\mathrm{LKH})$ independently screened titles and abstracts. All studies deemed eligible by at least one of the two reviewers were checked independently in full text by the same two reviewers. Disagreements between the reviewers about the inclusion of individual studies were discussed until consensus was reached. We recorded the reasons for excluding full-text RCTs.

Data collection. The following data were extracted from end-treatment follow-ups (immediately after the intervention) and follow-ups as close to 12 months as possible.

- Trial characteristics: location of the trial, number of patients allocated to the exercise and comparator groups respectively, number of patients in the intention to treat (ITT) and per protocol analysis, in the intervention and comparator groups respectively.

- Participant characteristics: Age, proportion of female, body mass index (BMI), baseline severity and diagnosis of the conditions, and number, type and frequency of other conditions.

- Intervention and comparator characteristics using the Template for Intervention Description and Replication (TIDieR) checklist (24). This includes 12 items that are: brief name of the intervention, why (rationale, theory, or goal of the elements essential to the intervention), what (materials used in the interventions), what (procedure activities, and/or processes used in the intervention), who provided the intervention (exercise physiologist), how (modes of delivery), where (type(s) of location(s) where the intervention occurred), when and how much (number of times the intervention was delivered), tailoring (If the intervention was planned to be personalised, titrated or adapted, then describe what, why, when, and how), modifications (if the intervention was modified during the study, describe the changes (what, why, when, and how), how well (planned adherence and fidelity), how well (actual adherence and fidelity).

- Outcome characteristics: time points assessed and the magnitude of objectively and subjectively measured changes (e.g., change in physical activity). To avoid multiplicity, we used a hierarchy of selection rules for the outcomes.

\section{Outcome selection hierarchy.}

- For objectively measured physical activity we prioritised: 1 ) accelerometers measures (e.g., daily time spent in moderate to vigorous physical activity); 2) pedometer (e.g., outcomes such as step counts); 3) any other outcome measure related to objectively measured physical activity.

- For subjectively measured physical activity we prioritised: 1) the Global Physical Activity Questionnaire; 2) the Physical Activity Scale for the Elderly (PASE) Questionnaire; 3) the International Physical Activity Questionnaires (IPAQ) long, short form and 
modified versions (e.g., for the elderly); 4) any other outcome measure related to subjectively measured physical activity.

- For weight loss outcome measures we prioritised: 1) reduction in Body Mass Index; 2) reduction in weight; 3 ) any other measure.

- For health-related quality of life we prioritised: 1) the EQ-5D questionnaire, 2) any other general health-related quality of life questionnaires (e.g., the 36-item Short-Form Health Survey physical component summary), 3) disease-specific health-related quality of life questionnaires (e.g., The Minnesota living with heart failure questionnaire).

- For objectively measured physical function, we prioritised: 1) the 6-minute walking test, 2) Incremental Shuttle Walking Test, 3) any other outcome measure related to daily function (e.g., Chair stand test).

- For self-reported physical function, we prioritised: 1) the SF-36 Physical Function subscale, 2) the SF-36 Role Function subscale, 3) any other self-reported measure of physical function.

For continuous outcomes we extracted the number of participants, mean and standard deviation, standard error or $95 \%$ Confidence Interval, $\mathrm{P}$ value, or other methods recommended by the Cochrane Collaboration (20). If the data could not be extracted from the published studies, we emailed the corresponding author a checklist including the data we aimed to obtain. If the email we sent bounced back, we contacted the second author and so forth. After three days, we sent a reminder. After seven days of the first email, we re-sent the email to the corresponding and last author. A second reminder followed ten days after the first email. We considered the data as missing after not receiving any communication from the authors fifteen days after sending the first email.

\section{Risk of bias assessment and overall evaluation of the quality of the evidence}

The two reviewers ( $\mathrm{AB}$ and $\mathrm{LKH}$ ) independently assessed the internal validity of all included trials using the Cochrane 'Risk of Bias Tool' (version 2.0). This tool includes the following domains: (1) Bias arising from the randomization process; (2) Bias due to deviations from the intended interventions; (3) Bias due to missing outcome data; (4) Bias in measurement of the outcome; (5) Bias in selection of the reported result. Within each domain, the two reviewers answered one or more signalling questions (e.g., Was the allocation sequence random? Were participants aware of their assigned intervention during the trial?) which led to judgments of "low risk of bias," "some concerns," or "high risk of bias". The judgments within each domain lead to an overall risk-of-bias judgment for the assessed outcome (20). Disagreements were resolved through discussion until consensus was reached. The overall quality of evidence for the estimates were evaluated using the GRADE (Grading of Recommendations Assessment, Development and Evaluation) approach (25). The GRADE is a systematic approach to rate the quality of evidence across studies for specific outcomes. It is based on five domains that involve the methodological flaws of the studies (i.e., risk of bias), the heterogeneity of results across studies (i.e., inconsistency), the generalisability of the findings to the target population (i.e., indirectness), the precision of the estimates and the risk of publication bias (25).

\section{Synthesis of results}

We performed meta-analysis to assess the effect of behavioural interventions on the outcomes of interest using a random-effects model as heterogeneity was expected due to differences in interventions, outcome measures etc. Heterogeneity was examined as between-study variance and calculated as the l-squared statistic measuring the proportion of variation in the combined estimates due to between study variance. An I-squared value of $0 \%$ indicates no inconsistency between the results of individual trials, and an I-squared value of $100 \%$ indicates maximal inconsistency. Standardised mean differences (SMD) with $95 \%$ Cls were calculated for outcome measures of continuous data but measured in different ways (e.g., all studies measured physical activity, but they use different objective tools) and adjusted to Hedges g. On the other hand, for outcomes of continuous data measured it in the same way (e.g., all studies measured weight loss assessing the BMI) the mean differences (MD) with 95\% Cls were calculated. The magnitude of the effect size of the pooled SMD was interpreted as 0.2 representing a small effect, 0.5 a moderate effect, and 0.8 a large effect (20). For outcome measures where a meta-analysis was not possible, a narrative data synthesis of the results from individual studies was performed in line with the guidance from the Cochrane handbook (20). When several intervention groups were compared to one control group, the number of participants in the control group was divided by the number of intervention groups, and each was analysed as a separate study comparison (20). 


\section{Meta-regression analyses, sensitivity analyses and additional analyses}

Pre-specified meta-regression analyses (22) were performed to explain heterogeneity by exploring the association of different BCTs, participants, trials and intervention characteristics with effect estimates. Since too few studies were included in the meta-analyses for physical activity and weight loss we did not perform meta-regression analysis for these outcomes according to the Cochrane Handbook (20). Instead, we investigated the association between BCTs and these outcomes narratively, by calculating the effectiveness ratios (i.e., the ratio of the number of times each BCT was used in an effective trial divided by the number of times they were a component of all trials using the $\mathrm{BCT}$ ) when at least three study comparisons were available. An effective trial was defined as a trial reporting a statistically significant between-group difference $(P<0.05)$ or a SMD $\pm 0.2(20)$ in favour of the intervention group.

We performed two sensitivity analyses to explore the robustness of the findings. First, given that physical activity and physical function are on the same continuum in the International Classification of Functioning, Disability and Health contextualisation, they were pooled together in one meta-analysis (26). Second, the meta-analysis on health-related quality of life was repeated, including the mental component scores instead of the physical component scores of the SF-12 (27-30). Furthermore, as the majority of the studies included patients with depression and targeted depression symptoms in addition to lifestyle behaviours, we also assessed the effect of behavioural intervention on depression symptoms.

\section{Patients' involvement}

The MOBILIZE project is committed to patient involvement and has so far included patients living with multimorbidity in all aspects of the decision-making process in the project. Their experiences, needs and preferences play an important role in developing a novel intervention (Collaborate level on the IAP2 Spectrum of Public Participation).

\section{Results}

\section{Study selection and characteristics}

The updated literature search identified a total of 1226 unique publications, of which 17 individual RCTs were identified and full texts screened for potential eligibility. We ultimately included 14 papers (see Additional file 2 for an overview). The included studies were conducted in 7 countries: USA (27, 28, 30-35), Croatia (36), Sweden (37), Iran (38), Turkey (39), Greece (40) and Taiwan (29) and were published from 2010 to 2019. The characteristics of the included studies are reported in Table 1.

\section{Participant characteristics}

The overall mean age of the participants $(n=1,378)$ included in the studies was 58.1 (SD \pm 4.7 ), of which $50.9 \%$ were female, mean a BMI was 32.5 (SD \pm 4.6 ). The most common combination of conditions reported was type 2 diabetes and depression in 6 studies (27, $29,30,33,35,36)$, diabetes and heart failure in 5 studies $(28,32,38-40)$, type 2 diabetes and heart failure in 2 studies $(31,37)$ and hypertension and type 2 diabetes in one study (34).

\section{Intervention and comparator groups characteristics}

All the interventions targeted lifestyle behaviours, including physical activity and healthy diet. The interventions were multifaceted and, in addition to usual care (e.g. counselling from their health care provider), the most commonly used components were exercise therapy in 8 studies $(27,32,35-40)$, cognitive behavioural therapy (CBT) in 4 studies $(27-29,32)$, patient education in 3 studies $(27,32,36)$, selfcare in 2 studies $(31,33)$, and motivation enhancement therapy (29), pharmacology (33) and behavioural activation (35) in one study. Exercise together with patient education and CBT or behavioural activation, were used in 3 studies $(27,32,35)$.

The comparator groups included usual care (e.g., counselling from their health care provider), psychoeducation, and CBT (Table 1). However, for the meta-analysis the comparator groups included were usual care groups.

The BCTs used in the included studies to target lifestyle behaviours such as physical activity and weight loss are reported in Additional File 3. Overall, the BCTs most commonly used were 'Instructions on how to perform the behaviour' (BCT 4.1) in all the studies but one 
(33), 'Social support unspecified' (BCT 3.1) in 11 studies $(27-29,31-35,38,39)$ and 'action planning' (BCT 1.4) in 9 studies $(27,28,30$, $32,35,37-40)$. The clusters of BCTs most commonly used were 'Goals and planning' and 'Feedback and monitoring' which were present 27 times in the 14 included studies.

\section{Outcome characteristics}

Physical activity was reported in 8 studies $(28,30,31,33-35,39,40)$, of which 5 used an objective assessment (e.g. accelerometer) (28, $30,35,39,40)$ and 3 a self-reported tools $(31,33,34)$. Weight loss was reported in 6 studies $(27-29,34,35,40)$ of which 5 studies reported data about the BMI of the participants and one as $\mathrm{Kg}(34)$. Physical function was reported in 7 studies $(27,28,30-32,37,38)$ of which 5 studies used an objective assessment (i.e. the 6 minutes walking test) $(27,28,31,32,37)$ and two used a self-reported tool (i.e. the SF-12) $(30,38)$. Health-related quality of life was reported in 10 studies $(27-33,37,39,40)$. Characteristics of the outcome measures are reported in Table 1.

\section{Effect of behavioural interventions on physical activity}

Five studies were included in the meta-analysis on physical activity. At the end-treatment follow-ups (mean 16 weeks (SD \pm 4 )), behavioural interventions appeared to have little effect on objectively measured physical activity (SMD $0.38,95 \% \mathrm{Cl}-0.12$ to $0.87 ; \mathrm{I}^{2}=$ 83.6\%) (Figure 1), however, the evidence is uncertain. Only one study (35) reported data on long term-follow ups (24 weeks post randomisation), showing no difference on objectively measured physical activity between the intervention and comparator group (SMD $0.13,95 \% \mathrm{Cl}-0.58$ to 0.84$)$.

Three studies assessed self-reported physical activity $(31,33,34)$. The results of these three studies were summarised narratively as no meta-analysis was deemed eligible due to large differences in reporting of the self-reported physical activity outcome measures. Overall, these three studies reported that the participants in the intervention groups were more physically active than the participants in the control groups at the end-treatment follow-up (mean 33 weeks, SD \pm 16 ). One study (31) reported that the percentage of participants physically active (i.e. having a Community Healthy Activities Model Program for Seniors (CHAMPS) questionnaire score $>6$ ) was $74.5 \%$ in the intervention group and $59.5 \%$ in the comparator group. Another study (33) reported that the percentage of participants physically active (two or more times per week) was $68.5 \%$ in the intervention group and $32.5 \%$ in the comparator group. While yet another study (34) reported that the participants in the intervention group improved their physical activity level (assessed with the CHAMPS questionnaires) more than the comparator group $(P<0.05)$.

\section{BCT associated with physical activity (objectively measured and self-reported).}

Overall, 12 BCTs were reported in at least 3 study comparisons at the end-treatment follow-up, and effectiveness ratios were calculated. Ten of the 12 BCTs tested had an effectiveness ratio of more or equal to 75\%, with the BCT 3.2 'social support (practical)' and BCT 1.4 'action planning' having an effectiveness ratio of $100 \%$ (Figure 2). At the follow-up closest to 12 months, we were unable to calculate effectiveness ratios due to insufficient data. Additional file 4 reported the raw data for calculating the effectiveness ratios.

\section{Effect of behavioural interventions on weight loss}

Five studies were included in the meta-analysis on weight loss $(27-29,35,40)$ with end-treatment follow-ups (mean 18 weeks (SD \pm 7 ). It is uncertain whether behavioural interventions have an effect on weight loss (BMI mean difference $-0.17,95 \% \mathrm{Cl}-1.17$ to $0.83: \mathrm{I}^{2}=13.3 \%$ ) (Figure 3). The study not included in a meta-analysis reported that the intervention group lost $1.8 \mathrm{~kg}(95 \% \mathrm{Cl}-4.3$ to 0.8$)$ more than the comparator group (34).

Two studies were included in the meta-analysis with long term follow-ups (24 months post randomisation) $(29,35)$ showing uncertainty for the effect of behavioural interventions on weight loss (BMI mean difference $-0.54,95 \% \mathrm{Cl}-2.70$ to $1.62 ; I^{2}=0.0 \%$ ) (Additional file 4 ).

\section{BCT associated with weight loss}

Overall, 11 BCTs were reported in at least 3 study comparisons, and effectiveness ratios were calculated. Five of the 11 BCT tested had an effectiveness ratio of more or equal to $75 \%$, with the BCT 3.2 'social support (practical) and BCT 1.4 'action planning' having an effectiveness ratio of $100 \%$ (Figure 4). At the follow-up closest to 12 months, we were unable to calculate effectiveness ratios due to insufficient data. Additional file 4 reports the raw data for calculating the effectiveness ratios.

\section{Effect of behavioural interventions on health-related quality of life}

Page 7/26 
Ten studies were included in meta-analysis on health related-quality of life at the end-treatment follow-up (mean 17 weeks (SD \pm 13 )). Behavioural interventions improved health-related quality of life (SMD 0.29, 95\% $\mathrm{Cl} 0.17$ to $0.42:\left.\right|^{2}=0.0 \%$ ) (Figure 5 ). Three studies were included in the meta-analysis with long term follow-ups (24 months post randomisation) $(28,29,32)$ and one study was included in the narrative synthesis. Meta-analysis showed that behavioural interventions may improve health-related quality of life (SMD $0.20,95 \% \mathrm{Cl}$ -0.05 to $0.46 ; I^{2}=0.0 \%$ ). However, the evidence was uncertain (Additional File 5 ), and the study included in the narrative synthesis showed no difference between the intervention and comparator group (36). We did not conduct meta-regression analyses or effectiveness ratio for health-related quality of life due to the non-existing statistical heterogeneity of the meta-analysis.

\section{Effect of behavioural interventions on physical function}

Eight studies were included in meta-analysis for physical function at the end-treatment follow-up (mean 12 weeks (SD \pm 5$)$ ). Behavioural interventions improved physical function (SMD 0.42, 95\% Cl -0.12 to $0.73: I^{2}=69.5 \%$ ) (Figure 6). Meta-regression analysis showed that increasing age was associated with higher effect sizes (slope $0.07,95 \% \mathrm{Cl} 0.02$ to 0.13 ) explaining $65 \%$ (Adjusted $\mathrm{R}^{2}$ ) of the inconsistency of the findings. A higher proportion of female participants in the studies was associated with lower effect sizes (slope $-0.02,95 \% \mathrm{Cl}-0.04$ to -0.01 ) explaining $36 \%$ (Adjusted $\mathrm{R}^{2}$ ) of the inconsistency of the findings. Meta-regression analysis also showed that studies using the BCT 2.1 'Monitoring of outcome of behaviour by others without feedback' were associated with a lower improvement in physical function than studies not using this BCT. Additionally, meta-regression analysis showed that studies using a higher number of BCTs for 'goal setting and planning' were associated with lower effect sizes (slope $-0.45,95 \% \mathrm{Cl}-0.72$ to -0.18 ) this explained $87 \%$ of the variations in the results of the meta-analysis (Additional File 6). Finally, a sub-group analysis showed that behavioural interventions including structured exercise session reported a moderate and possibly clinically relevant improvement (SMD $0.56,95 \% \mathrm{Cl} 0.08$ to 1.04 ) compared to interventions without a structured exercise session (SMD $0.25,95 \% \mathrm{Cl}-0.06$ to 0.56$)$ (Additional File 7).

One study, including two study comparisons, was included in the meta-analysis with long-term follow-up (24 weeks post randomisation). The study assessed physical function with the 6 minutes walking test and showed that behavioural interventions improved physical function (mean difference in meters walked in 6 minutes: $74.9,95 \% \mathrm{Cl} 0.01$ to $149.9 ; \mathrm{I}^{2}=0.0 \%$ ).

\section{Additional analyses}

Eleven studies were included in the additional analysis investigating the effect of behavioural interventions on depression symptoms. At the end-treatment follow-ups (mean 14 weeks (SD \pm 6 )) behavioural interventions reduced depression symptoms (SMD -0.70, 95\% CI -0.98 to $-0.42: 1^{2}=74.8 \%$ ) (Figure 7 ). At the long-term follow-up assessment there was no effect of behavioural interventions on depression symptoms (SMD $-0.38,95 \% \mathrm{Cl}-1.02$ to $0.26: \mathrm{I}^{2}=89.9 \%$ ). Meta-regression analysis showed that studies including people with a higher BMI (slope $0.9,95 \% \mathrm{Cl} 0.04$ to 0.15 ), studies using a higher number of $\mathrm{BCT}$ for 'goal setting and planning' (slope $0.31,95 \% \mathrm{Cl}$ 0.04 to 0.58 ) and 'Feedback and monitoring' (slope $0.25,95 \% \mathrm{Cl} 0.02$ to 0.48 ) were associated with a lower reduction of depression symptoms. Depression severity at baseline was not associated with depression symptoms reduction (slope $0.01,95 \% \mathrm{Cl}-0.02$ to 0.03 ).

\section{Sensitivity analyses}

In the sensitivity analyses analysing physical activity and physical function together, 10 studies (12 comparisons) were included. At the end-treatment follow-ups (mean 14 weeks $(S D \pm 6)$ ) behavioural interventions improved physical activity and physical function when combined (SMD 0.45, 95\% Cl 0.16 to $0.73: 1^{2}=69.6 \%$ ) (Figure 8 ).

Ten studies were included in the sensitivity for health-related quality of life (i.e., including the mental component scale data instead of the physical component score data for the studies using the SF-12). At the end-treatment follow-up, (mean 17 weeks (SD \pm 13 )) behavioural interventions improved health-related quality of life (SMD $0.30,95 \% \mathrm{Cl} 0.15$ to $\left.0.44: \mathrm{I}^{2}=0.0 \%\right)($ Figure 9$)$. These results are similar to the primary analysis results (Figure 6).

\section{Risk of bias and overall quality of the evidence}

The majority of the RCTs applied a proper randomisation process and reported and assessed the outcomes of interest correctly. Due to the nature of behavioural interventions, blinding of participants is challenging as patients receiving the intervention are also the outcome assessors of the patient-reported outcomes (Additional file 8). The overall quality of the evidence assessed using GRADE, including reasons for downgrading the quality of the evidence, is summarised in Table 2. 


\section{Discussion}

This systematic review included 14 papers from 7 countries and a total of 1,378 people with multimorbidity. Behavioural interventions targeting lifestyle behaviours improve health-related quality of life and physical function, reduce depression symptoms, and may have little to no effect on physical activity and weight loss in people with multimorbidity. However, the benefits diminish over time after the interventions ended.

\section{Overall results in context}

The small improvements for physical activity and weight loss observed are comparable to the short- and long-term improvements seen in behavioural interventions including people with single chronic diseases such as osteoarthritis (41), diabetes (42), heart disease (43), depression (44) and chronic obstructive pulmonary disease (45). A possible explanation for these findings is the lack of adherence to the intervention after the trials end. However, greater short-term effects on physical activity and weight loss may be achieved by using the BCT 1.4 'action planning' and the BCT 3.2 'social support (practical)', which may potentially have an impact on long term benefits as well (46).

The benefits of behavioural interventions on physical and psychosocial outcomes observed in this systematic review are greater than the findings from a previous systematic review focusing on behavioural interventions in multimorbidity in general (17). The focus on specific combinations of conditions, in our systematic review, may partially explain the differences in results between the two systematic reviews. However, direct comparisons of these findings should be interpreted with caution due to the different populations of the two systematic reviews.

Studies using exercise therapy as part of the behavioural interventions appeared to promote clinically relevant improvements in physical function. This is in line with another systematic review focusing on exercise therapy in people with multimorbidity (15). Furthermore, studies including a higher proportion of males or older people and those focusing on one BCT for 'goals and planning' relative to studies focusing on two or three BCTs for 'goals and planning', reported lower improvements in physical function. Similarly, using a higher number of BCTs for 'goals and planning' and 'feedback and monitoring' may reduce the effect of behavioural interventions on depression symptoms. This may be partially explained by the fact that focusing on many goals and being monitored in many aspects may be too burdensome for some patients. Finally, a higher reduction of depression symptoms was seen in people with lower BMI. However, with very few studies included limits our confidence in these results.

It is unclear why interventions targeting lifestyle behaviours, including physical activity and weight loss, improve physical and psychosocial outcomes but not necessarily behavioural outcomes. In this systematic review, two studies did not report an improvement in physical activity $(28,35)$. A possible explanation to this may be that either light intensity activities or sedentary time were not captured as they reported only the time spent performing moderate to vigorous activity (35). Or perhaps because increasing physical activity, although being a targeted behaviour of the intervention, was not the primary goal of the study (28). Physical activity may improve in people with multimorbidity when the intervention explicitly focuses on improving it (47).

\section{Research implications}

We suggest future studies using behavioural interventions to improve physical activity to test the BCTs and cluster of BCTs that appear to be associated with greater improvements and focus on people with combinations of conditions linked by common risk factors and pathogenesis. Additionally, since the short-term benefits diminish over time, possibly due to lack of adherence to the interventions once the trial has ended, we suggest future trials focus on strategies that may help the patients to adhere to the effective interventions and BCTs even after the intervention is finished. For example, booster sessions may help maintain physical activity levels (48). Furthermore, the content of the interventions received by the comparator groups was often not reported in sufficient details. This is unfortunately common (49), and we suggest authors of future studies follow, for example, the template for intervention description and replication (TIDieR) also for the comparator groups (24). Finally, we suggest future trials to also measure changes of light intensity physical activity as well as sedentary time, in line with the 2020 WHO guidelines for physical activity (50).

\section{Clinical implications}

To improve physical activity in people with multimorbidity, health-care professionals should consider encouraging, educating and planning together with the patients on what physical activity to do, when and how (BCT 1.4 'action planning'). Further, health-care professionals should advise or provide them with practical social support (BCT 3.2, e.g. provide a membership to a fitness centre and 
support by a qualified professional trained to deliver exercise therapy such as a physiotherapist or exercise physiologist). This may also help to achieve weight loss. To achieve greater improvements on physical function, we suggest focussing on one of the BCTs for 'goals and planning' rather than two or three. Also, it is advisable to avoid observing or recording outcomes of behaviour (e.g., physical activity) without providing feedback which appears to be associated with lower improvements in physical function. Similarly, using a higher number of BCTs for 'goals and planning' and 'feedback and monitoring' may reduce the effect of behavioural interventions on depression symptoms. Finally, particular attention should be paid to people with higher BMI, as they seem to be the sub-group of people with multimorbidity who benefit the least from reducing depression symptoms from behavioural interventions (51).

\section{Strengths and limitations}

The strengths of this systematic review are that we followed the Cochrane handbook recommendations for performing it and the PRISMA guidelines for reporting it, contacted authors of the included studies to retrieve additional data about their studies, pre-specified the main analyses, and followed a structured procedure to code BCTs. There are also limitations. Firstly, the too few studies matching our inclusion criteria reflected the inconsistency of the estimates of the meta-analyses and gave us low power for conducting the metaregression analyses for physical activity and weight loss. However, we provided a narrative synthesis to investigate the associations between BCTs and these outcomes, thereby providing the readers with useful data applicable in clinical practice and research (52-54). Secondly, the majority of the studies included people with depression and heart failure, and very few studies with other common combination of conditions. As an example, two out of three people with osteoarthritis have one or more other chronic conditions (55, 56). Finally, we potentially missed some of the BCTs used in the comparator groups who received usual care due to poor reporting of comparator interventions.

\section{Conclusions}

Behavioural intervention targeting lifestyle behaviours appear to have little or no effect on physical activity and weight loss in people with multimorbidity. By contrast, they improve health-related quality of life and physical function and reduce depression symptoms. Greater improvements in physical activity and weight loss may be achieved using the BCT 1.4 'action planning' and BCT 3.2 'social support (practical)'. However, these benefits diminished after the interventions terminated, highlighting the importance of further studies investigating strategies to maintain behaviour change and long-term effects.

\section{Declarations}

\section{Funding}

European Research Council (ERC) under the European Union's Horizon 2020 research and innovation programme (MOBILIZE, grant agreement No 801790), Næstved, Slagelse and Ringsted Hospitals' Research Fund and The Association of Danish Physiotherapists Research Fund. The funding source was not involved in any aspect of this systematic review protocol.

Dr. Skou and Ms. Zangger is currently funded by a program grant from Region Zealand (Exercise First).

\section{Data statements}

The dataset and statistical script necessary to reproduce the analyses presented in the systematic review will be made available online at the Open Science Framework page of the MOBILIZE project (https://osf.io/kfy32/).

\section{Competing interest}

The authors declare that they have no competing interests.

\section{Authors' contributions}

Page $10 / 26$ 
STS procured the funding for this systematic review. AB, MJäger and STS wrote the protocol of this systematic review. AB and LKH designed the search strategy and independently screened title/abstracts, full texts, extracted data from the included studies, assessed risk of bias and performed the GRADE assessment. AB contacted study authors to retrieve additional information. MJäger and GZ coded the BCT of the included studies and M Johnston soved disagreements. MJohnston and JM provided clinical expertees about behvaiour change. All authors read, provided feedback and approved the study design, methods, protocol and manuscript drafts as well as approved the final manuscript. $A B$ is the guarantor and drafted the manuscript.

\section{Acknowledgements}

We would like to thank Gregers Aagaard and Margit Dybkjær, two people living with multiple chronic conditions, and Tue Dybkjær a partner of a person with multimorbidity, for their feedback on the choice of the outcome measures for this systematic review and feedback on the presentation of the findings of this systematic review, respectively. We would also like to thank the MOBILIZE scientific advisory board consisting of Prof. Sallie Lamb, Prof. Alan Silman, Prof. Bente Klarlund Pedersen, Prof. Ewa M. Roos and Prof. Rod Taylor. Additionally, we would also like to thank the authors of the included studies which provided us the data requested via email: Brian C. Steinmeyer, Kenneth Freedland and Evangelia Kouidi.

\section{References}

1. Marengoni A, Angleman S, Melis R, Mangialasche F, Karp A, Garmen A, et al. Aging with multimorbidity: a systematic review of the literature. Ageing Res Rev. 2011;10(4):430-9.

2. Menotti A, Mulder I, Nissinen A, Giampaoli S, Feskens EJM, Kromhout D. Prevalence of morbidity and multimorbidity in elderly male populations and their impact on 10-year all-cause mortality: The FINE study (Finland, Italy, Netherlands, Elderly). J Clin Epidemiol. 2001;54(7):680-6.

3. Vogeli C, Shields AE, Lee TA, Gibson TB, Marder WD, Weiss KB, et al. Multiple chronic conditions: Prevalence, health consequences, and implications for quality, care management, and costs. J Gen Intern Med. 2007;22:391-5.

4. Bayliss EA, Bayliss MS, Ware JE, Jr., Steiner JF. Predicting declines in physical function in persons with multiple chronic medical conditions: what we can learn from the medical problem list. Health Qual Life Outcomes. 2004;2:47.

5. Fortin M, Lapointe L, Hudon C, Vanasse A, Ntetu AL, Maltais D. Multimorbidity and quality of life in primary care: a systematic review. Health Qual Life Outcomes. 2004;2:51.

6. Pefoyo AJ, Bronskill SE, Gruneir A, Calzavara A, Thavorn K, Petrosyan Y, et al. The increasing burden and complexity of multimorbidity. BMC Public Health. 2015;15:415.

7. Sinnott C, Mc Hugh S, Browne J, Bradley C. GPs' perspectives on the management of patients with multimorbidity: systematic review and synthesis of qualitative research. BMJ Open. 2013;3(9):e003610.

8. Muth C, Blom JW, Smith SM, Johnell K, Gonzalez-Gonzalez Al, Nguyen TS, et al. Evidence supporting the best clinical management of patients with multimorbidity and polypharmacy: a systematic guideline review and expert consensus. J Intern Med. 2019;285(3):272-88.

9. Vancampfort D, Koyanagi A, Ward PB, Rosenbaum S, Schuch FB, Mugisha J, et al. Chronic physical conditions, multimorbidity and physical activity across 46 low- and middle-income countries. Int J Behav Nutr Phys Act. 2017;14(1):6.

10. Chudasama YV, Khunti K, Gillies CL, Dhalwani NN, Davies MJ, Yates T, et al. Healthy lifestyle and life expectancy in people with multimorbidity in the UK Biobank: A longitudinal cohort study. PLoS Med. 2020;17(9):e1003332.

11. Michie S, Abraham C, Whittington C, McAteer J, Gupta S. Effective techniques in healthy eating and physical activity interventions: a meta-regression. Health Psychol. 2009;28(6):690-701.

12. O'Connor EA, Evans CV, Rushkin MC, Redmond N, Lin JS. Behavioral Counseling to Promote a Healthy Diet and Physical Activity for Cardiovascular Disease Prevention in Adults With Cardiovascular Risk Factors: Updated Evidence Report and Systematic Review for the US Preventive Services Task Force. JAMA. 2020;324(20):2076-94.

13. Buffel du Vaure C, Dechartres A, Battin C, Ravaud P, Boutron I. Exclusion of patients with concomitant chronic conditions in ongoing randomised controlled trials targeting 10 common chronic conditions and registered at ClinicalTrials.gov: a systematic review of registration details. BMJ Open. 2016;6(9):e012265. 
14. Michie S, Richardson M, Johnston M, Abraham C, Francis J, Hardeman W, et al. The behavior change technique taxonomy (v1) of 93 hierarchically clustered techniques: building an international consensus for the reporting of behavior change interventions. Ann Behav Med. 2013;46(1):81-95.

15. Bricca A, Harris LK, Jager M, Smith SM, Juhl CB, Skou ST. Benefits and harms of exercise therapy in people with multimorbidity: A systematic review and meta-analysis of randomised controlled trials. Ageing Res Rev. 2020;63:101166.

16. Smith SM, Bayliss EA, Mercer SW, Gunn J, Vestergaard M, Wyke S, et al. How to design and evaluate interventions to improve outcomes for patients with multimorbidity. J Comorb. 2013;3:10-7.

17. Smith SM, Wallace E, O'Dowd T, Fortin M. Interventions for improving outcomes in patients with multimorbidity in primary care and community settings. Cochrane Db Syst Rev. 2016(3).

18. Spring B, Champion KE, Acabchuk R, Hennessy EA. Self-regulatory behaviour change techniques in interventions to promote healthy eating, physical activity, or weight loss: a meta-review. Health Psychol Rev. 2020:1-32.

19. Diseases GBD, Injuries C. Global burden of 369 diseases and injuries in 204 countries and territories, 1990-2019: a systematic analysis for the Global Burden of Disease Study 2019. Lancet. 2020;396(10258):1204-22.

20. Higgins JPT TJ, Chandler J, Cumpston M, Li T, Page MJ, Welch VA (editors). Cochrane Handbook for Systematic Reviews of Interventions version 6.0 (updated July 2019). Cochrane, 2019. Available from www.training.cochrane.org/handbook. 2019.

21. Moher D, Liberati A, Tetzlaff J, Altman DG, Group P. Preferred reporting items for systematic reviews and meta-analyses: the PRISMA statement. BMJ. 2009;339:b2535.

22. Bricca A, Saracutu, M., Johnston, M., Zangger, G., Harris, L. K., Midtgaard, J., \& Skou, S. T. Effect of behavioural interventions on physical activity and weight loss in people with multimorbidity: protocol for a systematic review of randomised controlled trials. Retrieved from osfio/kfy32. 2020, August 19.

23. Smith SM, Wallace E, Salisbury C, Sasseville M, Bayliss E, Fortin M. A Core Outcome Set for Multimorbidity Research (COSmm). Ann Fam Med. 2018;16(2):132-8.

24. Hoffmann TC, Glasziou PP, Boutron I, Milne R, Perera R, Moher D, et al. Better reporting of interventions: template for intervention description and replication (TIDieR) checklist and guide. Bmj-Brit Med J. 2014;348.

25. Schünemann H BJ, Guyatt G, Oxman A, editors. . GRADE handbook for grading quality of evidence and strength of recommendations. Updated October 2013. The GRADE Working Group, 2013. Available fromguidelinedevelopment.org/handbook. 2013.

26. World Health O. International classification of functioning, disability and health : ICF. Geneva: World Health Organization; 2001.

27. de Groot M, Shubrook JH, Hornsby Jr WG, Pillay Y, Mather KJ, Fitzpatrick K, et al. Program ACTIVE II: Outcomes From a Randomized, Multistate Community-Based Depression Treatment for Rural and Urban Adults With Type 2 Diabetes. Diabetes Care. 2019;42(7):1185-93.

28. Freedland KE, Carney RM, Rich MW, Steinmeyer BC, Rubin EH. Cognitive Behavior Therapy for Depression and Self-Care in Heart Failure Patients: A Randomized Clinical Trial. JAMA Intern Med. 2015;175(11):1773-82.

29. Huang CY, Lai HL, Chen Cl, Lu YC, Li SC, Wang LW, et al. Effects of motivational enhancement therapy plus cognitive behaviour therapy on depressive symptoms and health-related quality of life in adults with type II diabetes mellitus: a randomised controlled trial. Qual Life Res. 2016;25(5):1275-83.

30. Piette JD, Richardson C, Himle J, Duffy S, Torres T, Vogel M, et al. A randomized trial of telephonic counseling plus walking for depressed diabetes patients. Med Care. 2011;49(7):641-8.

31. Dunbar SB, Reilly CM, Gary R, Higgins MK, Culler S, Butts B, et al. Randomized clinical trial of an integrated self-care intervention for persons with heart failure and diabetes: quality of life and physical functioning outcomes. J Card Fail. 2015;21(9):719-29.

32. Gary RA, Dunbar SB, Higgins MK, Musselman DL, Smith AL. Combined exercise and cognitive behavioral therapy improves outcomes in patients with heart failure. Journal of psychosomatic research. 2010;69(2):119-31.

33. Katon WJ, Lin EH, Von Korff M, Ciechanowski P, Ludman EJ, Young B, et al. Collaborative care for patients with depression and chronic illnesses. N Engl J Med. 2010;363(27):2611-20.

34. Lynch EB, Liebman R, Ventrelle J, Avery EF, Richardson D. A self-management intervention for African Americans with comorbid diabetes and hypertension: a pilot randomized controlled trial. Prev Chronic Dis. 2014;11:E90.

35. Schneider KL, Panza E, Handschin B, Ma Y, Busch AM, Waring ME, et al. Feasibility of Pairing Behavioral Activation With Exercise for Women With Type 2 Diabetes and Depression: the Get It Study Pilot Randomized Controlled Trial. Behavior therapy.

Page 12/26 
2016;47(2):198-212.

36. Pibernik-Okanovic M, Hermanns N, Ajdukovic D, Kos J, Prasek M, Sekerija M, et al. Does treatment of subsyndromal depression improve depression-related and diabetes-related outcomes? A randomised controlled comparison of psychoeducation, physical exercise and enhanced treatment as usual. Trials. 2015;16:305.

37. Asa C, Maria S, Katharina SS, Bert A. Aquatic Exercise Is Effective in Improving Exercise Performance in Patients with Heart Failure and Type 2 Diabetes Mellitus. Evid-Based Compl Alt. 2012.

38. Keihani DK, M; Mokhtari, M. Cardiac effects of exercise rehabilitation on quality of life,

depression and anxiety in patients with heart failure patients. Journal of Fundamentals of Mental Health. $2014 ; 17$ (1):13-9.

39. Kulcu DG, Kurtais Y, Tur BS, Gulec S, Seckin B. The effect of cardiac rehabilitation on quality of life, anxiety and depression in patients with congestive heart failure. A randomized controlled trial, short-term results. Europa medicophysica. 2007;43(4):489-97.

40. Koukouvou G, Kouidi E, lacovides A, Konstantinidou E, Kaprinis G, Deligiannis A. Quality of life, psychological and physiological changes following exercise training in patients with chronic heart failure. Journal of rehabilitation medicine. 2004;36(1):36-41.

41. Williamson W, Kluzek S, Roberts N, Richards J, Arden N, Leeson P, et al. Behavioural physical activity interventions in participants with lower-limb osteoarthritis: a systematic review with meta-analysis. BMJ Open. 2015;5(8):e007642.

42. Aguiar EJ, Morgan PJ, Collins CE, Plotnikoff RC, Callister R. Efficacy of interventions that include diet, aerobic and resistance training components for type 2 diabetes prevention: a systematic review with meta-analysis. Int J Behav Nutr Phys Act. $2014 ; 11: 2$.

43. Graham H, Prue-Owens K, Kirby J, Ramesh M. Systematic Review of Interventions Designed to Maintain or Increase Physical Activity Post-Cardiac Rehabilitation Phase II. Rehabil Process Outc. 2020;9.

44. Lambert JD, Greaves CJ, Farrand P, Price L, Haase AM, Taylor AH. Web-Based Intervention Using Behavioral Activation and Physical Activity for Adults With Depression (The eMotion Study): Pilot Randomized Controlled Trial. J Med Internet Res. 2018;20(7):e10112.

45. Mantoani LC, Rubio N, McKinstry B, MacNee W, Rabinovich RA. Interventions to modify physical activity in patients with COPD: a systematic review. Eur Respir J. 2016;48(1):69-81.

46. Sniehotta FF, Schwarzer R, Scholz U, Schuz B. Action planning and coping planning for long-term lifestyle change: Theory and assessment. Eur J Soc Psychol. 2005;35(4):565-76.

47. Lo YP, Chiang SL, Lin CH, Liu HC, Chiang LC. Effects of Individualized Aerobic Exercise Training on Physical Activity and HealthRelated Physical Fitness among Middle-Aged and Older Adults with Multimorbidity: A Randomized Controlled Trial. Int $\mathrm{J}$ Environ Res Public Health. 2020;18(1).

48. Scott EJ, Dimairo M, Hind D, Goyder E, Copeland RJ, Breckon JD, et al. "Booster" interventions to sustain increases in physical activity in middle-aged adults in deprived urban neighbourhoods: internal pilot and feasibility study. BMC Public Health. 2011;11:129.

49. de Bruin M, Black N, Javornik N, Viechtbauer W, Eisma MC, Hartman-Boyce J, et al. Underreporting of the active content of behavioural interventions: a systematic review and meta-analysis of randomised trials of smoking cessation interventions. Health Psychol Rev. 2020:1-19.

50. Bull FC, Al-Ansari SS, Biddle S, Borodulin K, Buman MP, Cardon G, et al. World Health Organization 2020 guidelines on physical activity and sedentary behaviour. Br J Sports Med. 2020;54(24):1451-62.

51. Luppino FS, de Wit LM, Bouvy PF, Stijnen T, Cuijpers P, Penninx BW, et al. Overweight, obesity, and depression: a systematic review and meta-analysis of longitudinal studies. Arch Gen Psychiatry. 2010;67(3):220-9.

52. Willett M, Duda J, Fenton S, Gautrey C, Greig C, Rushton A. Effectiveness of behaviour change techniques in physiotherapy interventions to promote physical activity adherence in lower limb osteoarthritis patients: A systematic review. PLoS One. 2019;14(7):e0219482.

53. Bishop FL, Fenge-Davies AL, Kirby S, Geraghty AW. Context effects and behaviour change techniques in randomised trials: a systematic review using the example of trials to increase adherence to physical activity in musculoskeletal pain. Psychol Health. 2015;30(1):104-21.

54. Martin J, Chater A, Lorencatto F. Effective behaviour change techniques in the prevention and management of childhood obesity. Int J Obes (Lond). 2013;37(10):1287-94.

55. Wesseling J, Welsing PM, Bierma-Zeinstra SM, Dekker J, Gorter KJ, Kloppenburg M, et al. Impact of self-reported comorbidity on physical and mental health status in early symptomatic osteoarthritis: the CHECK (Cohort Hip and Cohort Knee) study.

Page $13 / 26$ 
Rheumatology (Oxford). 2013;52(1):180-8.

56. Muckelt PE, Roos EM, Stokes M, McDonough S, Gronne DT, Ewings S, et al. Comorbidities and their link with individual health status: A cross-sectional analysis of 23,892 people with knee and hip osteoarthritis from primary care. J Comorb. 2020;10:2235042X20920456.

\section{Tables}

TABLE 1. Study, participant, intervention and outcome characteristics of the included studies. 


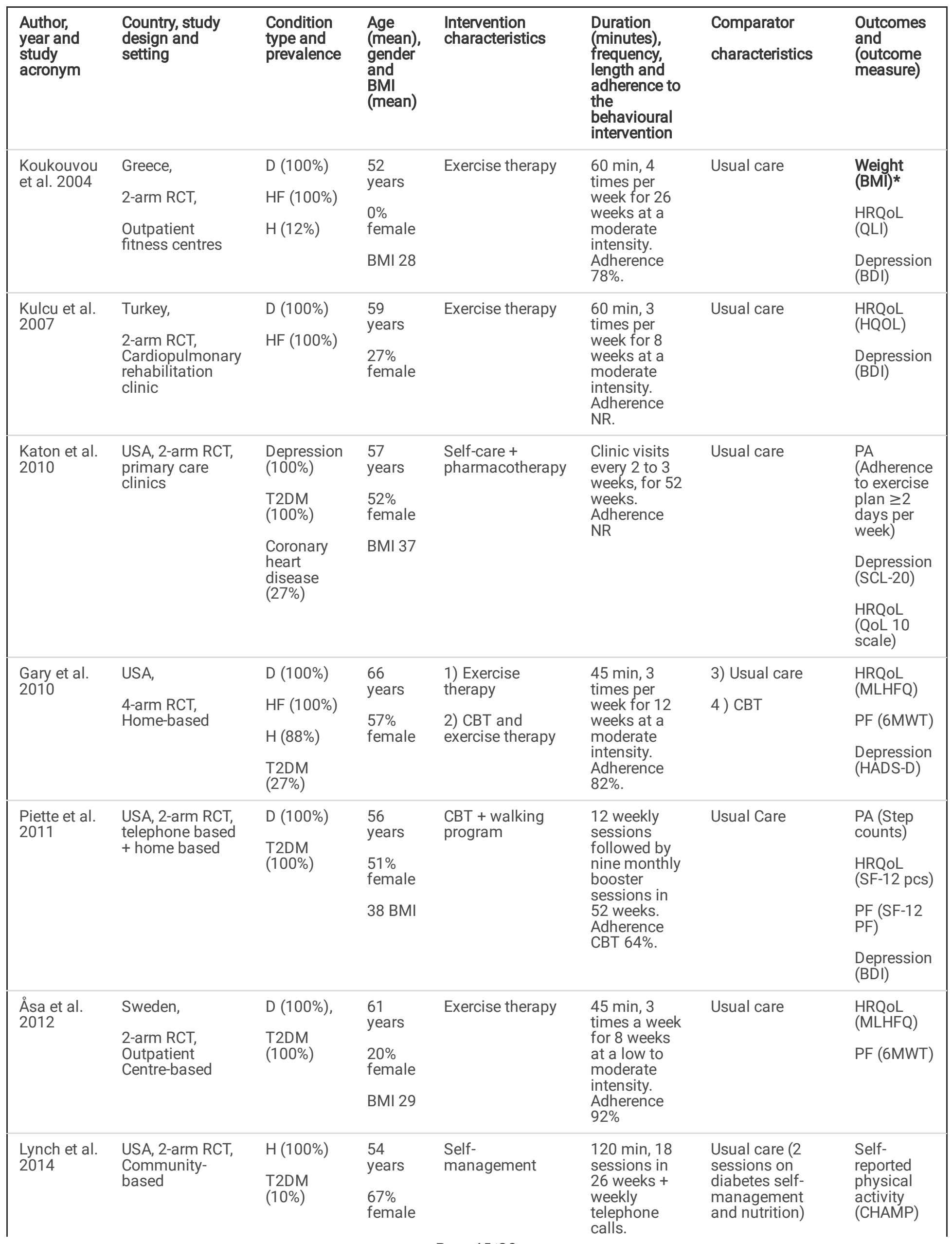

Page 15/26 


\begin{tabular}{|c|c|c|c|c|c|c|c|}
\hline & & & $36 \mathrm{BMI}$ & & $\begin{array}{l}\text { Adherence } \\
\text { NR }\end{array}$ & & $\begin{array}{l}\text { Weight } \\
\text { loss (Kg) }\end{array}$ \\
\hline \multirow{2}{*}{$\begin{array}{l}\text { Dunbar et } \\
\text { al. } 2015\end{array}$} & \multirow{2}{*}{$\begin{array}{l}\text { USA, 2-arm RCT, } \\
\text { home-based and } \\
\text { clinic based. }\end{array}$} & $\mathrm{HF}(100 \%)$ & \multirow{2}{*}{$\begin{array}{l}57 \\
\text { years, } \\
34 \% \\
\text { female, } \\
\text { BMI } 37\end{array}$} & \multirow{2}{*}{$\begin{array}{l}\text { Integrated Self- } \\
\text { Care } \\
\text { Intervention + } \\
\text { Usual care }\end{array}$} & \multirow[b]{2}{*}{$\begin{array}{l}\text { One } \\
\text { individualised } \\
\text { counselling } \\
\text { session with } \\
\text { family } \\
\text { members + } \\
\text { one home } \\
\text { visit by the } \\
\text { research } \\
\text { nurse + four } \\
\text { telephone call } \\
\text { + one visit } \\
\text { clinic. } \\
\text { Duration } 17 \\
\text { weeks. } \\
\text { Adherence } \\
\text { NR }\end{array}$} & \multirow[t]{2}{*}{ Usual care } & \multirow{2}{*}{$\begin{array}{l}\text { PA } \\
\text { (CHAMP) }\end{array}$} \\
\hline & & $\begin{array}{l}\text { T2DM } \\
(100 \%)\end{array}$ & & & & & \\
\hline \multirow{4}{*}{$\begin{array}{l}\text { Keihani et } \\
\text { al } 2015\end{array}$} & & $\mathrm{D}(100 \%)$ & \multirow{4}{*}{$\begin{array}{l}61 \\
\text { years } \\
40 \% \\
\text { female } \\
\text { BMI } 29\end{array}$} & \multirow[t]{4}{*}{ Exercise therapy } & \multirow{4}{*}{$\begin{array}{l}60 \text { min, } 3 \\
\text { times per } \\
\text { week for } 8 \\
\text { weeks at a } \\
\text { moderate } \\
\text { intensity. } \\
\text { Adherence } \\
\text { NR }\end{array}$} & \multirow[t]{4}{*}{ Usual care } & \multirow{4}{*}{$\begin{array}{l}\text { PF (SF-36 } \\
\text { PF) } \\
\text { Depression } \\
\text { (BDI-D) }\end{array}$} \\
\hline & 2-arm RCT, & $\operatorname{HF}(100 \%)$ & & & & & \\
\hline & $\begin{array}{l}\text { institute of } \\
\text { cardiovascular } \\
\text { rehabilitation in }\end{array}$ & & & & & & \\
\hline & Isfahan & & & & & & \\
\hline \multirow{5}{*}{$\begin{array}{l}\text { Freedland } \\
\text { et al } 2015\end{array}$} & \multirow{5}{*}{$\begin{array}{l}\text { USA, 2-arm RCT, } \\
\text { academic centre }\end{array}$} & D (100\%) & \multirow{5}{*}{$\begin{array}{l}56 \\
\text { years, } \\
46 \% \\
\text { female, } \\
36 \text { BMI }\end{array}$} & \multirow[t]{5}{*}{$\mathrm{CBT}+$ usual care } & \multirow{5}{*}{$\begin{array}{l}60 \text { min, once } \\
\text { per week for } \\
26 \text { weeks and } \\
4 \text { telephone } \\
\text { calls from } \\
\text { week } 26 \text { to } \\
52 .\end{array}$} & \multirow[t]{5}{*}{ Usual care } & \multirow{2}{*}{$\begin{array}{l}\text { PA } \\
\text { (Actigraphy } \\
\text { 7-d } \\
\text { average } \\
\text { activity) }\end{array}$} \\
\hline & & HF $(100 \%)$ & & & & & \\
\hline & & & & & & & PF (6MWT) \\
\hline & & & & & & & $\begin{array}{l}\text { Depression } \\
\text { BDI-II) }\end{array}$ \\
\hline & & & & & & & $\begin{array}{l}\text { Weight } \\
\text { loss (BMI)* }\end{array}$ \\
\hline \multirow{3}{*}{$\begin{array}{l}\text { Pibernik- } \\
\text { Okanović } \\
\text { et al. } 2015\end{array}$} & Croatia, & D (100\%) & $\begin{array}{l}66 \\
\text { years }\end{array}$ & \multirow[t]{3}{*}{ Exercise therapy } & \multirow{3}{*}{$\begin{array}{l}75 \text { min, for } \\
\text { once a week } \\
\text { for } 6 \text { weeks. } \\
\text { Adherence } \\
\text { NR. }\end{array}$} & \multirow{3}{*}{$\begin{array}{l}\text { 1) Enhanced } \\
\text { usual care } \\
\text { 2) } \\
\text { Psychoeducation }\end{array}$} & \multirow{3}{*}{$\begin{array}{l}\text { HRQoL } \\
\text { (SF-12) } \\
\text { Depression } \\
\text { (CES-D) }\end{array}$} \\
\hline & $\begin{array}{l}\text { 3-arm RCT, } \\
\text { Tertiary diabetes } \\
\text { clinic }\end{array}$ & $\begin{array}{l}\text { T2DM } \\
(100 \%)\end{array}$ & $\begin{array}{l}54 \% \\
\text { female }\end{array}$ & & & & \\
\hline & & & BMI 30 & & & & \\
\hline \multirow{3}{*}{$\begin{array}{l}\text { Huang et } \\
\text { al. } 2016\end{array}$} & \multirow{3}{*}{$\begin{array}{l}\text { Taiwan, 2-arm } \\
\text { RCT, clinic }\end{array}$} & D (100\%) & \multirow{3}{*}{$\begin{array}{l}54 \\
\text { years, } \\
52 \% \\
\text { female, } \\
\text { BMI } 26\end{array}$} & \multirow{3}{*}{$\begin{array}{l}\mathrm{CBT}+ \\
\text { motivational } \\
\text { enhancement } \\
\text { therapy + usual } \\
\text { care }\end{array}$} & \multirow{3}{*}{$\begin{array}{l}80 \text { min, once } \\
\text { a week for } 12 \\
\text { weeks (4 } \\
\text { weeks of } \\
\text { motivational } \\
\text { enhancement } \\
\text { therapy and } 8 \\
\text { CBT } \\
\text { sessions), }\end{array}$} & \multirow[t]{3}{*}{ Usual care } & \multirow{3}{*}{$\begin{array}{l}\text { Weight } \\
\text { loss (BMI) } \\
\text { HRQoL } \\
\text { (SF-12 pcs) } \\
\text { Depression } \\
\text { (CES-D) }\end{array}$} \\
\hline & & $\begin{array}{l}\text { T2DM } \\
(100 \%)\end{array}$ & & & & & \\
\hline & & & & & & & \\
\hline \multirow{3}{*}{$\begin{array}{l}\text { Schneider } \\
\text { et al. } 2016\end{array}$} & USA, & D $(100 \%)$ & 53 & Exercise therapy & $90 \mathrm{~min}, 2$ & Enhanced Usual & Depression \\
\hline & $\begin{array}{l}\text { 2-arm RCT, } \\
\text { University of } \\
\text { Massachusetts } \\
\text { Medical }\end{array}$ & $\begin{array}{l}\text { T2DM } \\
(100 \%)\end{array}$ & $\begin{array}{l}100 \% \\
\text { female }\end{array}$ & & $\begin{array}{l}\text { week for } 12 \\
\text { weeks at a } \\
\text { moderate } \\
\text { intensity. }\end{array}$ & $\begin{array}{l}\text { to inform } \\
\text { participants on } \\
\text { their condition) }\end{array}$ & (BDI-II) \\
\hline & School's & & BMI 31 & & $\begin{array}{l}\text { Adherence } \\
51 \%\end{array}$ & & \\
\hline $\begin{array}{l}\text { de Groot et } \\
\text { al. } 2019\end{array}$ & USA, & D (100\%), & $\begin{array}{l}56 \\
\text { years }\end{array}$ & $\begin{array}{l}\text { 1) Exercise } \\
\text { therapy: }\end{array}$ & $\begin{array}{l}50 \mathrm{~min} \\
\text { (10min warm }\end{array}$ & 1) $\mathrm{CBT}$ & $\begin{array}{l}\text { Depression } \\
\text { (BDI-II) }\end{array}$ \\
\hline (ACTIVE II) & $\begin{array}{l}\text { 2-arm RCT, } \\
\text { Community } \\
\text { fitness centers }\end{array}$ & $\begin{array}{l}\text { T2DM } \\
(100 \%)\end{array}$ & $\begin{array}{l}77 \% \\
\text { female }\end{array}$ & $\begin{array}{l}\text { 2) Exercise } \\
\text { therapy and } \mathrm{CBT}\end{array}$ & $\begin{array}{l}\text { up and } 10 \mathrm{~min} \\
\text { cool down) } 2 \\
\text { times per }\end{array}$ & dal care & $\begin{array}{l}\text { HRQoL } \\
\text { (SF-12 pcs) }\end{array}$ \\
\hline
\end{tabular}


BDI=Beck depression inventory, BDI-II= Beck depression inventory II, BMI=Body mass index, CES-D= Center for Epidemiologic Studies Depression Scale, COPD=chronic obstructive pulmonary disease, $\mathrm{D}=$ Depression, EuroQol-VAS= EQ quality of life visual analogue scale, $\mathrm{GDS}=$ Geriatric depression scale, $\mathrm{H}=$ Hypertension, $\mathrm{HF}=$ heart failure, HADS-D=Hospital and anxiety depression scale for depression(D), $\mathrm{HbA1c}=$ Haemoglobin A1c, HQOL= Hacettepe Quality of Life Questionnaire, HRQoL=health related quality of life, MLHFQ=Minnesota Living with Heart Failure Questionnaire, $\mathrm{PF}=$ physical function, $6 \mathrm{MWT}=$ six-minute walking test, $\mathrm{RCT}=$ randomised controlled trial, PA=Physical activity, PHQ-9=Patient Health Questionnaire-9, QLI= Quality of Life Index, SCL-20= Symptom Checklist-20, SF-12=12-Item Short Form Health Survey, SF-36= 36-Item Long Form Health Survey, T2DM=type 2 diabetes mellitus. *=data retrieved upon request from the authors of the study.

Table 2. Summary of findings table 


\begin{tabular}{|c|c|c|c|c|}
\hline Outcomes & $\begin{array}{l}\text { Risk with } \\
\text { Behavioural } \\
\text { intervention }\end{array}$ & $\begin{array}{l}\text { № of } \\
\text { participants } \\
\text { (studies) }\end{array}$ & $\begin{array}{l}\text { Certainty of } \\
\text { the } \\
\text { evidence } \\
\text { (GRADE) }\end{array}$ & Comments \\
\hline $\begin{array}{l}\text { Physical } \\
\text { activity } \\
\text { assessed } \\
\text { with: } \\
\text { Objectively } \\
\text { measured } \\
\text { follow up: } \\
\text { mean } 16 \\
\text { weeks }\end{array}$ & $\begin{array}{l}\text { SMD } 0.38 \\
\text { SD higher } \\
\text { (0.12 lower } \\
\text { to } 0.87 \\
\text { higher) }\end{array}$ & $\begin{array}{l}548 \\
\text { (5 RCTs) }\end{array}$ & $\underset{\substack{\text { VERY LOW } \\
\text { a,b,c }}}{\bigoplus \text { POP }}$ & $\begin{array}{l}\text { Behavioural intervention may increase/have little to no effect on } \\
\text { physical activity, at the end of the interventions, but the evidence is } \\
\text { very uncertain. Greater short-term effects may be achieved using } \\
\text { the BCT } 1.4 \text { 'action planning' and the BCT } 3.2 \text { 'social support } \\
\text { (practical)'. The evidence is very uncertain for long term } \\
\text { effectiveness }(k=1) \text {. }\end{array}$ \\
\hline $\begin{array}{l}\text { Physical } \\
\text { activity } \\
\text { assessed } \\
\text { with: Self- } \\
\text { reported } \\
\text { follow up: } \\
\text { range } 24 \\
\text { weeks to } \\
52 \text { weeks }\end{array}$ & not pooled & $\begin{array}{l}344 \\
\text { (3 RCTs) }\end{array}$ & $\underset{\substack{\text { VERY LOW } \\
\text { b,d }}}{\bigoplus \text { POP }}$ & $\begin{array}{l}\text { The evidence is very uncertain about the effect of behavioural } \\
\text { intervention on physical activity. The three studies included } \\
\text { reported that the participants in the intervention groups were more } \\
\text { physically active than the participants in the comparator groups at } \\
\text { the end-treatment follow-up (mean } 33 \text { weeks, SD } \pm 16 \text { ). Greater } \\
\text { short-term effects may be achieved by using the BCT } 1.4 \text { 'action } \\
\text { planning' and the BCT } 3.2 \text { 'social support (practical)'. No } \\
\text { assessments were made at long-term follow-ups. }\end{array}$ \\
\hline $\begin{array}{l}\text { Weight } \\
\text { loss } \\
\text { follow up: } \\
\text { mean } 18 \\
\text { weeks }\end{array}$ & $\begin{array}{l}\text { MD } 0.17 \\
\text { SD lower } \\
\text { (1.17 lower } \\
\text { to } 0.83 \\
\text { higher) }\end{array}$ & $\begin{array}{l}356 \\
\text { (5 RCTs) }\end{array}$ & $\underset{\substack{\text { VERY LOW } \\
\text { a,b,c }}}{\bigoplus P O O}$ & $\begin{array}{l}\text { The evidence is very uncertain about the effect of behavioural } \\
\text { intervention on weight loss. One study not included in meta- } \\
\text { analysis (due to the heterogenous weight loss outcome } \\
\text { measurement) reported that the intervention group lost } 1.8 \mathrm{~kg}(95 \% \\
\text { Cl - } 4.3 \text { to } 0.8) \text { more than the comparator group. Greater short-term } \\
\text { effects may be achieved using the BCT } 1.4 \text { 'action planning' and } \\
\text { the BCT } 3.2 \text { 'social support (practical)". The evidence is very } \\
\text { uncertain also at long-term follow-ups ( } \mathrm{k}=2) \text {. }\end{array}$ \\
\hline $\begin{array}{l}\text { Health- } \\
\text { related } \\
\text { quality of } \\
\text { life } \\
\text { follow up: } \\
\text { mean } 17 \\
\text { weeks }\end{array}$ & $\begin{array}{l}\text { SMD } 0.29 \\
\text { SD higher } \\
\text { ( } 0.17 \text { higher } \\
\text { to } 0.42 \\
\text { higher) }\end{array}$ & $\begin{array}{l}1052 \\
\text { (10 RCTs) }\end{array}$ & $\begin{array}{l}\bigoplus \bigoplus \bigoplus \bigoplus \text { MODERATE } \\
\text { b }\end{array}$ & $\begin{array}{l}\text { Behavioural intervention likely increases the health-related quality } \\
\text { of life slightly. At long term follow-ups, the effect seems to diminish } \\
\text { slightly }(\mathrm{k}=2) \text {, but the evidence is uncertain. }\end{array}$ \\
\hline $\begin{array}{l}\text { Physical } \\
\text { function } \\
\text { follow up: } \\
\text { mean } 12 \\
\text { weeks }\end{array}$ & $\begin{array}{l}\text { SMD } 0.42 \\
\text { SD higher } \\
\text { (0.12 higher } \\
\text { to } 0.73 \\
\text { higher) }\end{array}$ & $\begin{array}{l}1042 \\
\text { (10 RCTs) }\end{array}$ & $\begin{array}{l}\bigoplus \bigoplus_{\text {LW }} \bigoplus^{\mathrm{b}} \mathrm{O} \\
\end{array}$ & $\begin{array}{l}\text { Behavioural intervention likely increases physical function slightly. } \\
\text { Increasing age, a higher proportion of male participants, and } \\
\text { interventions using structured exercise sessions reported higher } \\
\text { effect sizes at the end-treatment follow-ups. Interventions, } \\
\text { including structured exercise sessions, reported a moderate and } \\
\text { possibly clinically relevant improvement compared to interventions } \\
\text { without structured exercise sessions. Using the BCT 'Monitoring of } \\
\text { outcome of behaviour without feedback' and a higher number of } \\
\text { BCT used for "Goals Settings and Planning" was associated with } \\
\text { lower effect sizes at the end-treatment follow-ups. At long-term } \\
\text { follow-ups (k=1) the effects seemed sustained. }\end{array}$ \\
\hline $\begin{array}{l}\text { Depression } \\
\text { symptoms } \\
\text { follow up: } \\
\text { mean } 14 \\
\text { weeks }\end{array}$ & $\begin{array}{l}\text { SMD } 0.7 \\
\text { SD lower } \\
\text { (0.98 lower } \\
\text { to } 0.42 \\
\text { lower) }\end{array}$ & $\begin{array}{l}1038 \\
\text { (11 RCTs) }\end{array}$ & $\begin{array}{l}\bigoplus \bigoplus \bigoplus \bigoplus \text { MODERATE } \\
\text { a }\end{array}$ & $\begin{array}{l}\text { Behavioural intervention likely reduces depression symptoms. } \\
\text { Studies including people with a higher BMl, using a higher number } \\
\text { of BCTs for 'goal setting and planning' and using the BCT } \\
\text { 'feedback and monitoring without feedback' were associated with a } \\
\text { lower reduction of depression symptoms. Depression severity was } \\
\text { not associated with effect sizes. At the long-term follow-ups the } \\
\text { effect of behavioral intervention diminished. }\end{array}$ \\
\hline \multicolumn{5}{|c|}{$\begin{array}{l}\text { *The risk in the intervention group (and its } 95 \% \text { confidence interval) is based on the assumed risk in the comparison group and the } \\
\text { relative effect of the intervention (and its } 95 \% \mathrm{Cl} \text { ). } \\
\text { Cl: Confidence interval; SMD: Standardised mean difference; MD: Mean difference }\end{array}$} \\
\hline \multicolumn{5}{|c|}{$\begin{array}{l}\text { GRADE Working Group grades of evidence } \\
\text { High certainty: We are very confident that the true effect lies close to that of the estimate of the effect } \\
\text { Moderate certainty: We are moderately confident in the effect estimate: The true effect is likely to be close to the estimate of the } \\
\text { effect, but there is a possibility that it is substantially different } \\
\text { Low certainty: Our confidence in the effect estimate is limited: The true effect may be substantially different from the estimate of } \\
\text { the effect } \\
\text { Very low certainty: We have very little confidence in the effect estimate: The true effect is likely to be substantially different from the } \\
\text { estimate of effect }\end{array}$} \\
\hline
\end{tabular}




\section{Explanations}

1. Quality of evidence downgraded of one level for inconsistency of the estimates

2. Quality of evidence downgraded of one level for indirectness of the population

3. Quality of evidence downgraded of one level for imprecision of the estimates

4. Quality of the evidence downgraded of one level for inconsistency of the outcome measurements

\section{Figures}

\begin{tabular}{|c|c|c|c|c|c|c|c|c|}
\hline \multirow[b]{2}{*}{ Study } & \multicolumn{3}{|c|}{ Treatment } & \multicolumn{3}{|c|}{ Control } & \multirow{2}{*}{$\begin{array}{c}\text { SMD } \\
\text { with } 95 \% \mathrm{Cl}\end{array}$} & \multirow{2}{*}{$\begin{array}{c}\text { Weight } \\
(\%)\end{array}$} \\
\hline & $\mathrm{N}$ & Mean & SD & $\mathrm{N}$ & Mean & SD & & \\
\hline Freedland 2015 & 79 & 91 & 59 & 79 & 98.8 & 58.5 & $-0.14[-0.45,0.17]$ & 23.93 \\
\hline Schneider 2016 & 15 & 17 & 9.7 & 14 & 17.8 & 14.9 & $-0.06[-0.77,0.65]$ & 17.18 \\
\hline Kulcu 2007 & 23 & 7.2 & 2.8 & 21 & 6.5 & 1.4 & $0.31[-0.28,0.89]$ & 19.33 \\
\hline Piette 2011 & 145 & 4499 & 2612 & 146 & 3226 & 1860 & $0.56[0.33,0.79]$ & 24.95 \\
\hline Koukouvou 2004 & 16 & 13 & 2.5 & 10 & 9.5 & 1.2 & $1.52[0.65,2.38]$ & 14.60 \\
\hline Overall & & & & & & & $0.38[-0.12,0.87]$ & \\
\hline \multicolumn{9}{|c|}{ Heterogeneity: $\mathrm{T}^{2}=0.24, \mathrm{I}^{2}=83.59 \%, \mathrm{H}^{2}=6.09$} \\
\hline \multicolumn{9}{|c|}{ Test of $\theta_{i}=\theta_{j}: Q(4)=20.81, p=0.00$} \\
\hline \multicolumn{9}{|c|}{ Test of $\theta=0: z=1.49, p=0.14$} \\
\hline & & & & & & & & \\
\hline
\end{tabular}

Random-effects REML model

Favors comparators Favors behavioral interventions

\section{Figure 1}

Forest plot for the effect of behavioural interventions compared to a usual care comparator group on objectively measured physical function. SMD = Standardised Mean Difference; $95 \% \mathrm{Cl}=95 \%$ Confidence Interval. 


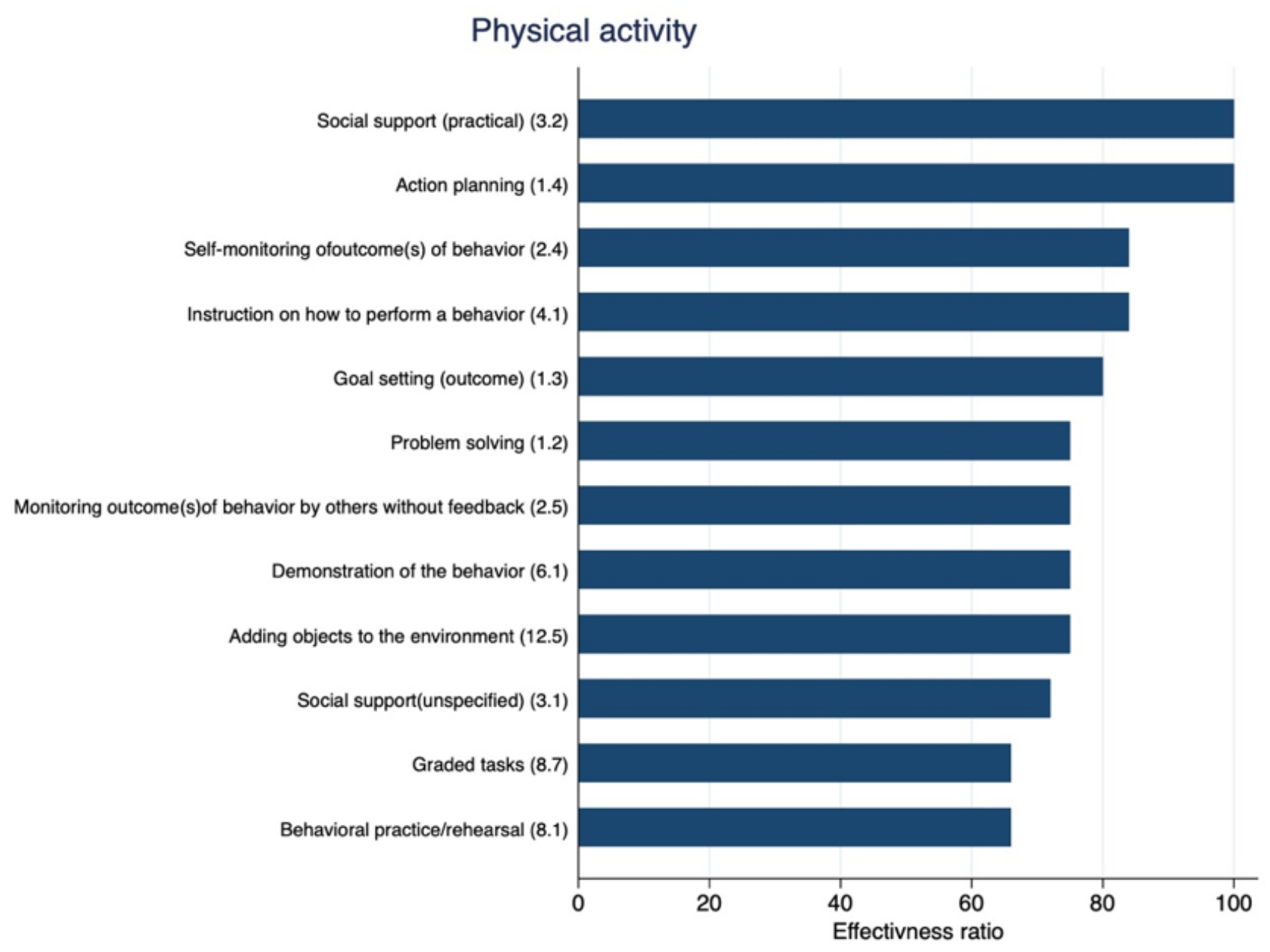

Figure 2

Effectivness ratio of BCTs in behavioural randomised controlled trials including people with multimorbidity. Effectivness ratio= number of times each BCT was used in an effective trial divided by the number of times they were a component of all trials using the BCT; the higher the ratio the more often the BCT was found effective out of the total number of trials included.

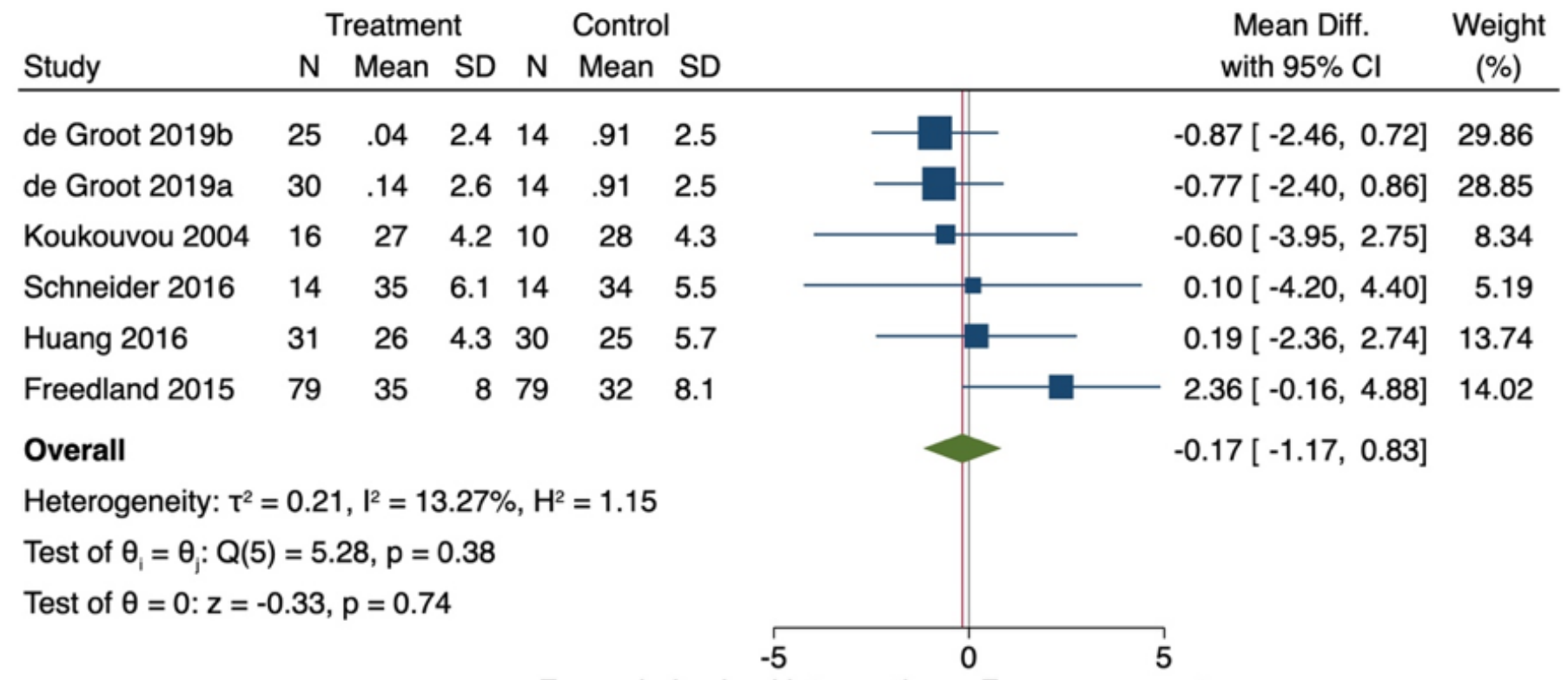




\section{Figure 3}

Forest plot for the effect of behavioural interventions compared to a usual care comparator group on weight loss (Body Mass Index). 95 $\% \mathrm{Cl}=95 \%$ Confidence Interval. a,b=two separate study comparisons from the same study.

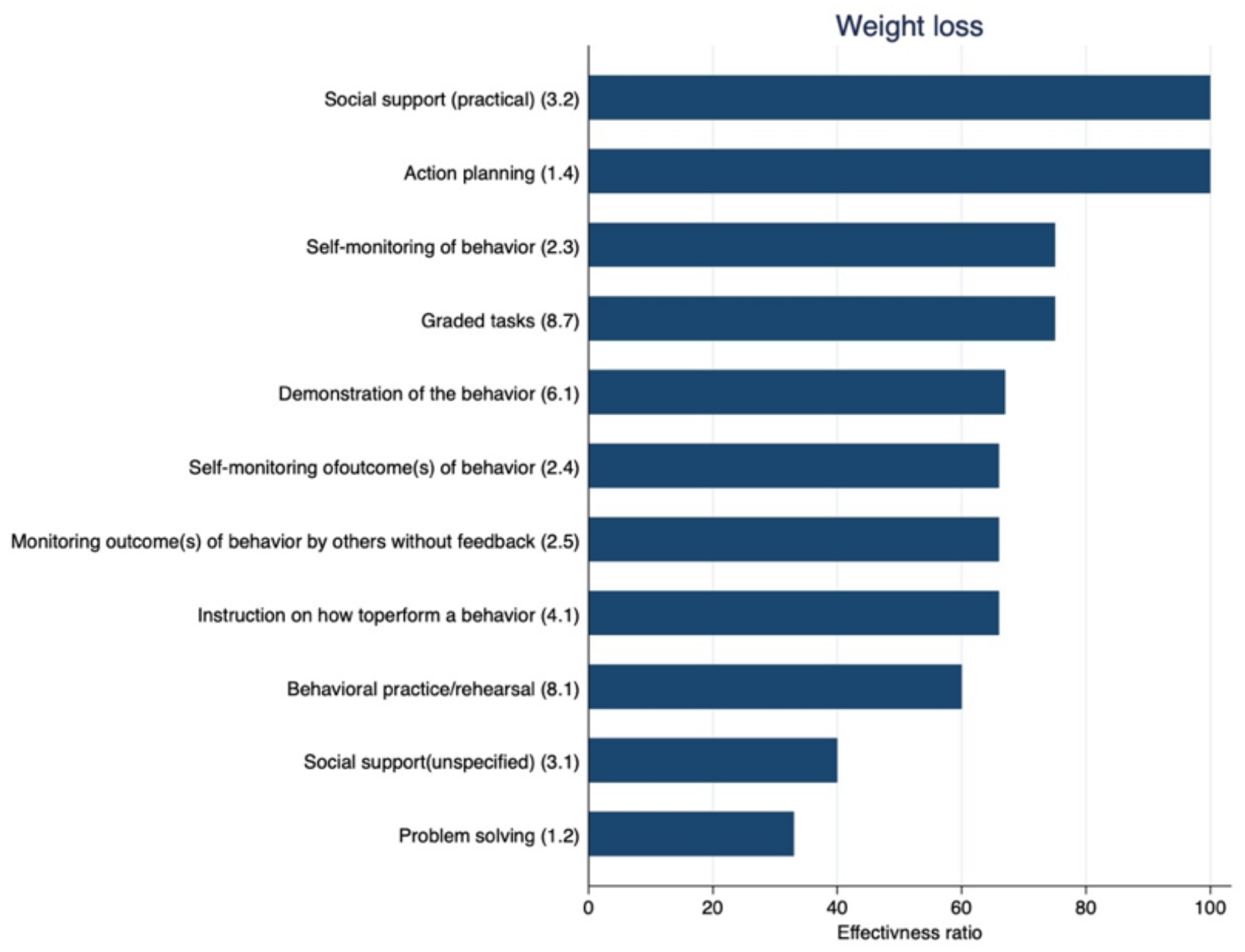

\section{Figure 4}

Effectivness ratio of BCTs in behavioural randomised controlled trials including people with multimorbidity. Effectivness ratio= number of times each BCT was used in an effective trial divided by the number of times they were a component of all trials using the BCT; the higher the ratio the more often the BCT was found effective out of the total number of trials included. 


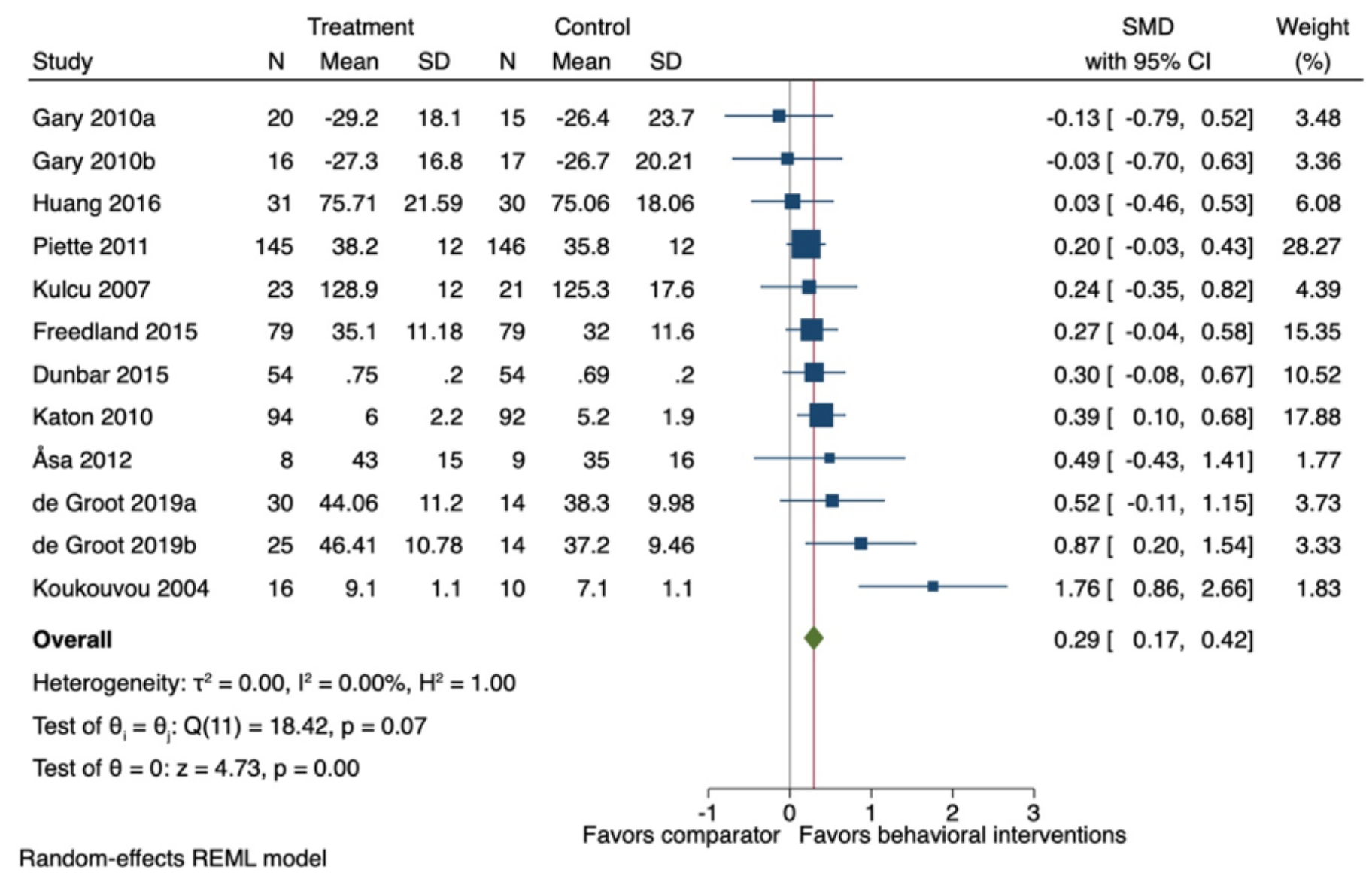

\section{Figure 5}

Forest plot for the effect of behavioural interventions compared to a usual care comparator group on health-related quality of life. SMD = Standardised Mean Difference; $95 \% \mathrm{Cl}=95 \%$ Confidence Interval. a,b=two separate study comparisons from the same study. 


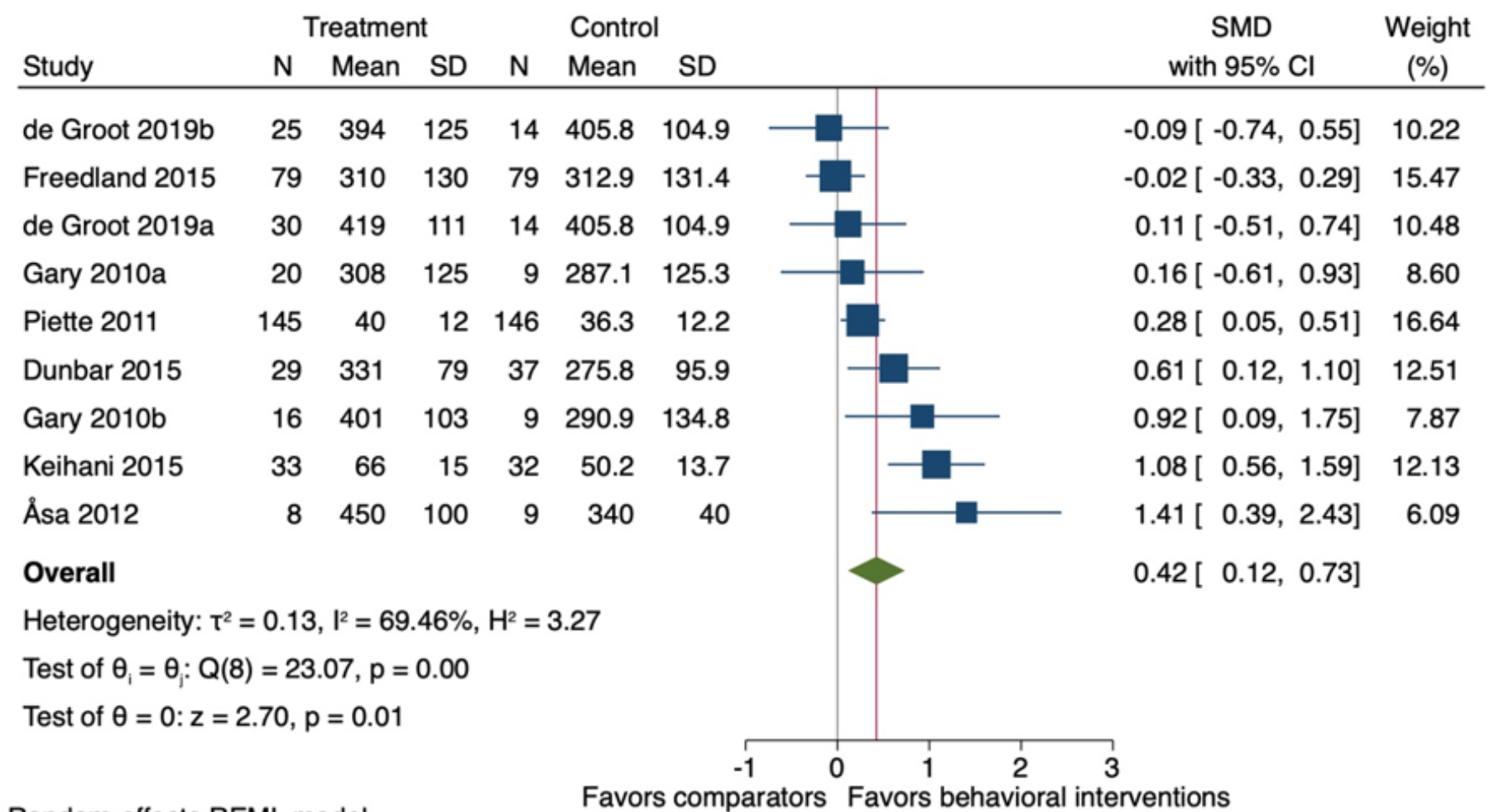

\section{Random-effects REML model}

Favors comparators Favors behavioral interventions

\section{Figure 6}

Forest plot for the effect of behavioural interventions compared to a usual care comparator group on physical function. SMD = Standardised Mean Difference; $95 \% \mathrm{Cl}=95 \%$ Confidence Interval. a,b=two separate study comparisons from the same study. 


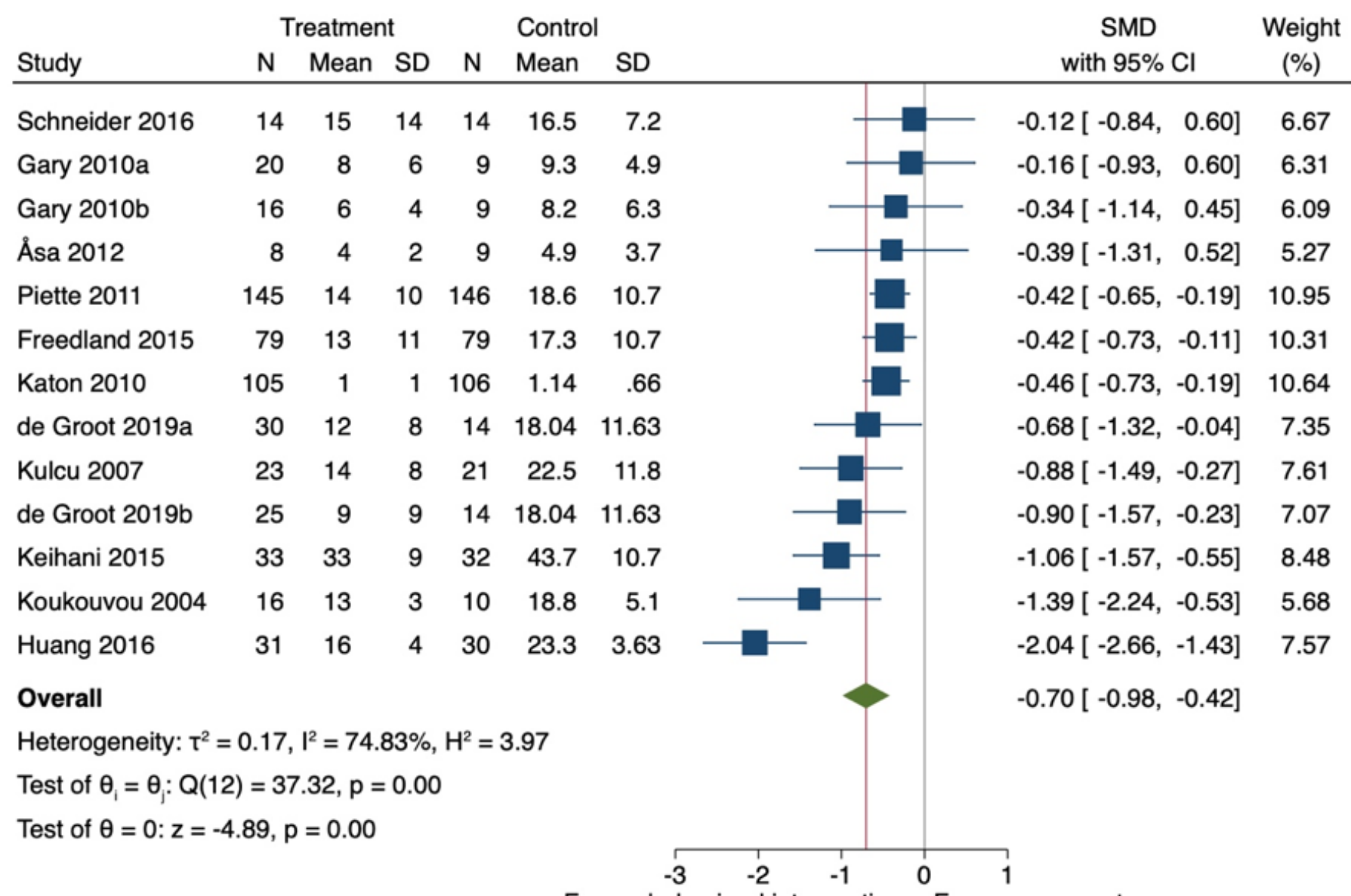

Random-effects REML model

Favors behavioral interventions Favors comparator

Figure 7

Forest plot for the effect of behavioural interventions compared to a usual care comparator group on depression symptoms. SMD = Standardised Mean Difference; $95 \% \mathrm{Cl}=95 \%$ Confidence Interval. a,b=two separate study comparisons from the same study. 


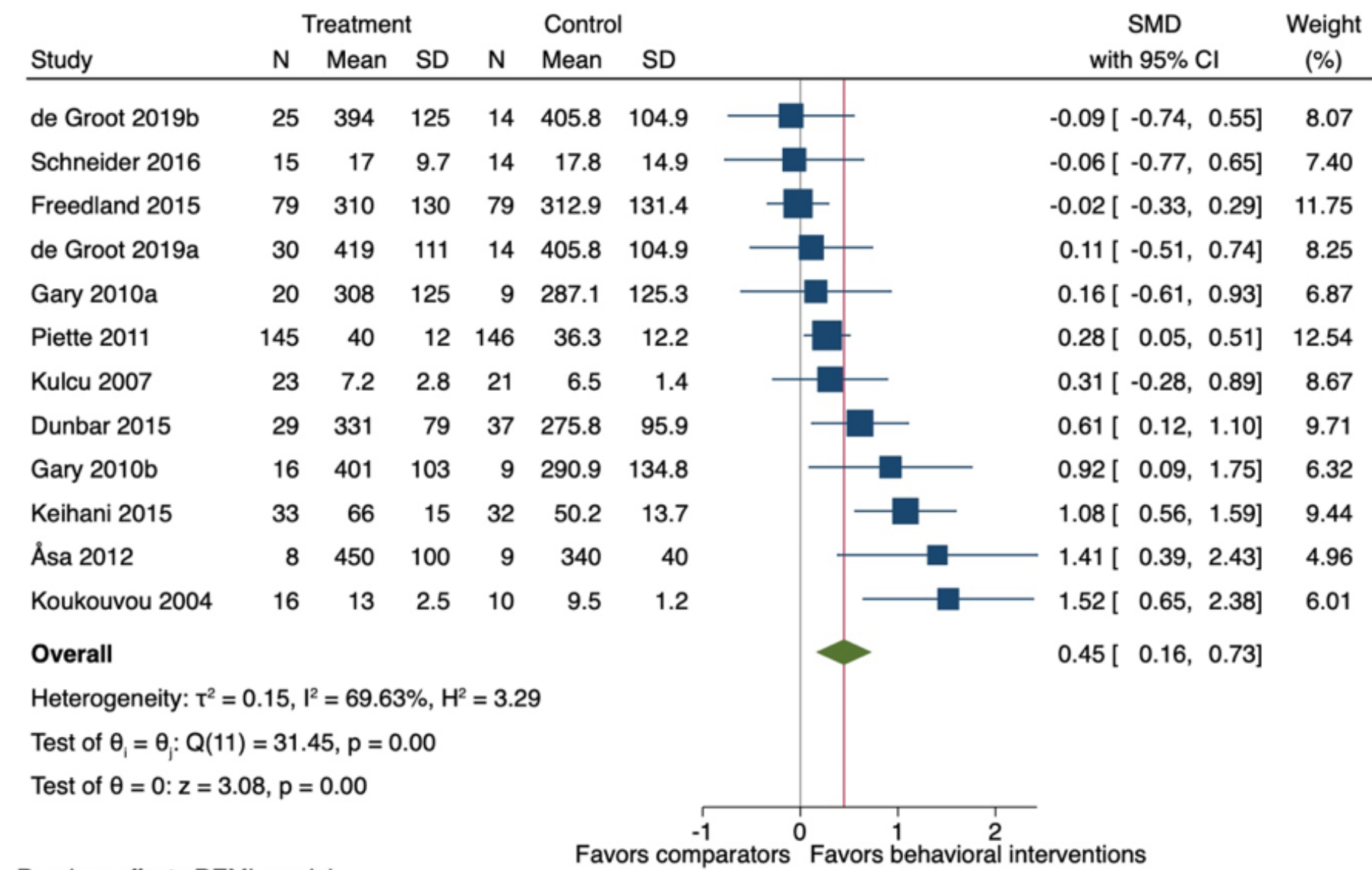

Random-effects REML model

Figure 8

Forest plot for the effect of behavioural interventions compared to a usual care comparator group on physical activity and physical function. SMD = Standardised Mean Difference; $95 \% \mathrm{Cl}=95 \%$ Confidence Interval. a,b=two separate study comparisons from the same study. 


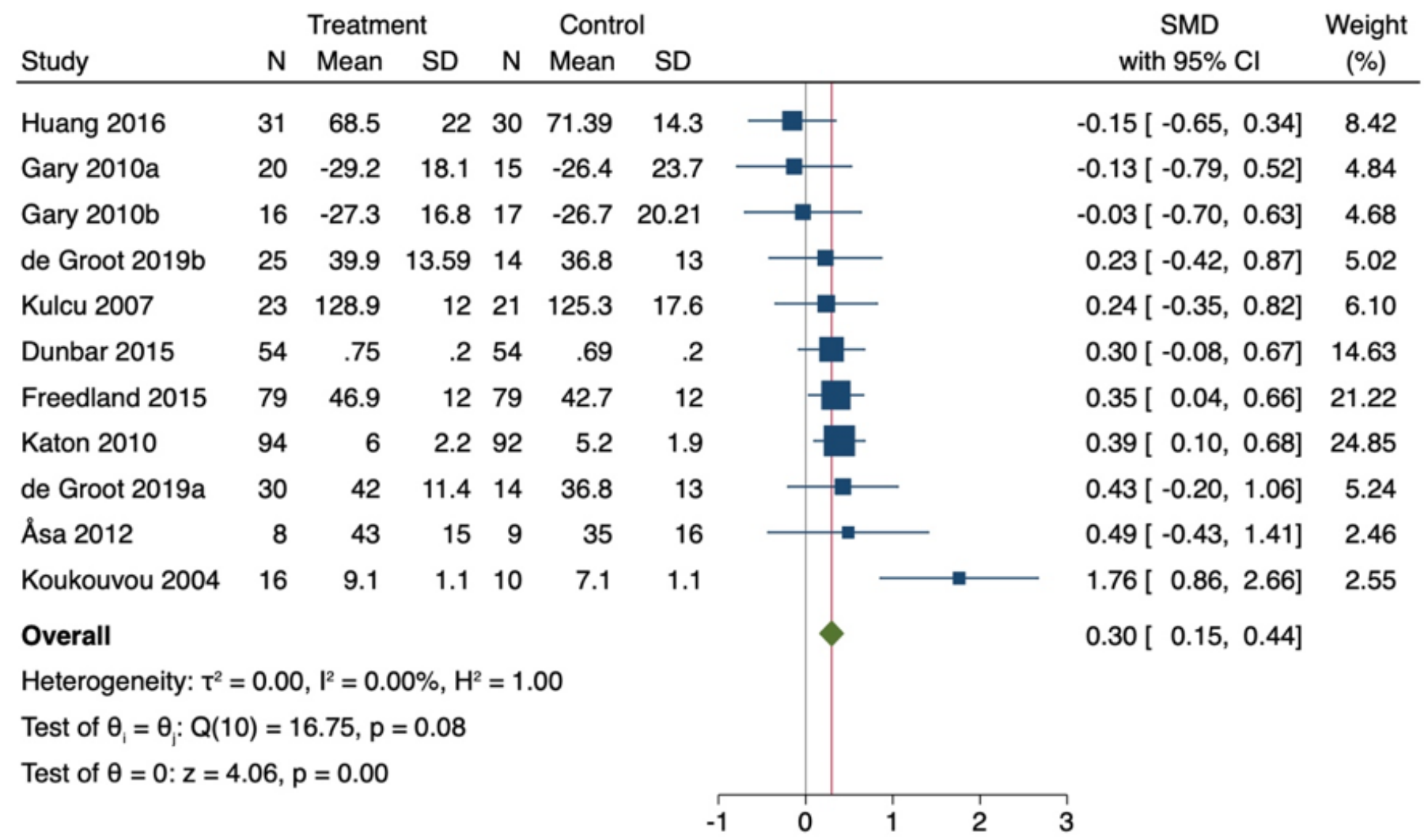

Random-effects REML model

Favors comparator Favors behavioral interventions

Sorted by:_meta_es

\section{Figure 9}

Forest plot for the effect of behavioural interventions compared to a usual care comparator group on health-related quality of life. SMD

= Standardised Mean Difference; $95 \% \mathrm{Cl}=95 \%$ Confidence Interval. a,b=two separate study comparisons from the same study.

\section{Supplementary Files}

This is a list of supplementary files associated with this preprint. Click to download.

- Additionalfilessubmit.docx 